\title{
Internal Intraseasonal Variability of the West African Monsoon in WRF $\mathscr{O}$
}

\author{
GHASSAN J. Alaka JR. \\ Cooperative Institute for Marine and Atmospheric Studies, University of Miami, and NOAA/AOML/Hurricane \\ Research Division, Miami, Florida \\ ERIC D. MALONEY \\ Department of Atmospheric Science, Colorado State University, Fort Collins, Colorado
}

(Manuscript received 17 October 2016, in final form 22 February 2017)

\begin{abstract}
The West African monsoon (WAM) and its landmark features, which include African easterly waves (AEWs) and the African easterly jet (AEJ), exhibit significant intraseasonal variability in boreal summer. However, the degree to which this variability is modulated by external large-scale phenomena, such as the Madden-Julian oscillation (MJO), remains unclear. The Weather Research and Forecasting (WRF) Model is employed to diagnose the importance of the MJO and other external influences for the intraseasonal variability of the WAM and associated AEW energetics by removing 30-90-day signals from initial and lateral boundary conditions in sensitivity tests. The WAM produces similar intraseasonal variability in the absence of external influences, indicating that the MJO is not critical to produce WAM variability. In control and sensitivity experiments, AEW precursor signals are similar near the AEJ entrance in East Africa. For example, an eastward extension of the AEJ increases barotropic and baroclinic energy conversions in East Africa prior to a 30-90-day maximum of perturbation kinetic energy in West Africa. The WAM appears to prefer a faster oscillation when MJO forcing is removed, suggesting that the MJO may serve as a pacemaker for intraseasonal oscillations in the WAM. WRF results show that eastward propagating intraseasonal signals (e.g., Kelvin wave fronts) are responsible for this pacing, while the role of westward propagating intraseasonal signals (e.g., MJO-induced Rossby waves) appears to be limited. Mean state biases across the simulations complicate the interpretation of results.
\end{abstract}

\section{Introduction}

The West African monsoon (WAM) is a thermally driven circulation that regulates North African rainfall in boreal summer (Lafore et al. 2010). The WAM is a complex system, with several jets and circulations contained within a $40^{\circ}$ band of latitude that spans latitudes from south of the equator to Europe. Two key features of the WAM are the African easterly jet (AEJ) and African easterly waves (AEWs), which seed the majority of Atlantic tropical cyclones (e.g., Landsea et al. 1998; Thorncroft and Hodges 2001). Positioned in North

Supplemental information related to this paper is available at the Journals Online website: http://dx.doi.org/10.1175/ JCLI-D-16-0750.s1.

Corresponding author: Ghassan J. Alaka, ghassan.alaka@noaa. gov
Africa near $15^{\circ} \mathrm{N}$ and vertically near $650 \mathrm{hPa}$, the AEJ is in thermal wind balance with a strong meridional temperature gradient that exists between the Saharan heat low and the Gulf of Guinea during boreal summer. The AEJ extends hundreds of kilometers into the Atlantic Ocean and enhances midlevel cyclonic vorticity in the Atlantic main development region for tropical cyclones (Goldenberg and Shapiro 1996).

AEWs are atmospheric eddies that grow via energy conversions afforded by the WAM system, including baroclinic and barotropic conversions associated with the AEJ (Norquist et al. 1977; Hsieh and Cook 2007; Alaka 2014; Alaka and Maloney 2014, hereafter AM2014). AEWs, best known as seed disturbances for most Atlantic tropical cyclones (Landsea et al. 1998), propagate westward at $8.5-12 \mathrm{~m} \mathrm{~s}^{-1}$ and have a periodicity of 2.5-6 days (Kiladis et al. 2006; Wu et al. 2013). East Africa (east of $10^{\circ} \mathrm{E}$ ) has been identified as an initiation region for AEWs for several decades (Carlson 


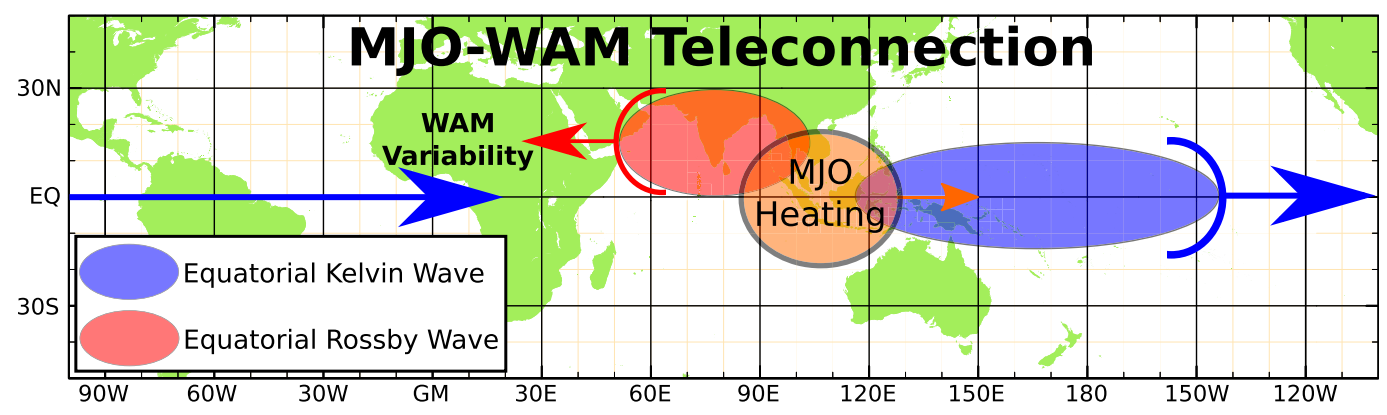

FIG. 1. Simple view of equatorial Kelvin waves (blue) and equatorial Rossby waves (red), both initiated by MJO heating (orange) according to Heckley and Gill (1984), propagating into tropical North Africa. Arrows are colorcoded to show propagation of each phenomenon.

1969). Specifically, upstream convective anomalies near the Darfur Mountains and Ethiopian highlands grow upscale into mature AEWs (Hall et al. 2006; Kiladis et al. 2006; Mekonnen et al. 2006; Thorncroft et al. 2008; Leroux and Hall 2009; Alaka and Maloney 2012).

Prominent intraseasonal variability of the WAM has important consequences for boreal summer precipitation in the rain-sensitive Sahel region and the amplitude of AEWs entering the east Atlantic (Janicot et al. 2009; Alaka and Maloney 2012, 2014). Given that up to $50 \%$ of annual rainfall in the Sahel is associated with convective systems embedded within AEWs, the intraseasonal variability of these phenomena is crucial to the improvement of precipitation forecasts in this water-sensitive region (Crétat et al. 2015). Additionally, increased WAM convection and stronger AEW activity on intraseasonal time scales may be associated with increased tropical cyclogenesis in the Atlantic main development region for tropical cyclones (Ventrice et al. 2011). Despite the intraseasonal oscillation of the WAM being well documented in the literature, the extent to which this variability is internally or externally driven is unclear. For example, the Madden-Julian oscillation (MJO; Madden and Julian 1971; Zhang 2005) may be a primary source of externally driven intraseasonal variability in the WAM.

Several studies have linked the MJO to WAM variability through the initiation of equatorial waves that propagate from the Indo-Pacific warm pool to tropical Africa (Matthews 2004; Maloney and Shaman 2008; Janicot et al. 2009; Ventrice et al. 2011; Alaka and Maloney 2012, 2014). In particular, MJO-induced eastward-propagating Kelvin waves and westwardpropagating Rossby waves appear to impact convection and large-scale cyclonic shear associated with the AEJ, which supports stronger AEW variability (Matthews 2004). The MJO and its associated equatorial waves may also influence AEW energetics, especially barotropic and baroclinic energy conversions, which govern AEW initiation and growth across North Africa (AM2014). Similarly, equatorial Kelvin wave fronts initiated by the MJO may impact easterly wave activity and associated energetics in the east Pacific prior to propagating into the WAM region (Rydbeck et al. 2013; Rydbeck and Maloney 2014). The pathways by which Kelvin and Rossby waves propagate into North Africa are shown in Fig. 1.

However, the extent to which the MJO modulates intraseasonal variability in the WAM is still up for debate, as is the mechanism behind this modulation. On the one hand, Ventrice et al. (2011) linked MJO-related convective variability in the WAM to equatorial Rossby waves and claimed that enhanced cyclonic shear is induced by the passage of MJO-induced equatorial Kelvin waves. On the other hand, Alaka and Maloney (2012) suggested that both MJO-induced dry equatorial Kelvin waves and equatorial Rossby waves modulate convection and AEW initiation in East Africa. Recently, AM2014 demonstrated that a multivariate MJO index (e.g., Wheeler and Hendon 2004) can explain only about $10 \%$ of the intraseasonal variability of AEWs in West Africa, which suggests that influence of the MJO on West Africa is limited.

Complex topography and diverse land cover throughout North Africa point to the potential importance of internal processes for producing intraseasonal variability in the WAM (Mounier et al. 2008; Janicot et al. 2011), suggesting that the WAM may exhibit intraseasonal variability without influence from the MJO. For example, Mounier et al. (2008) found that convection in the WAM and central Atlantic exhibits 10-25-day internal oscillations. In addition, convection in the Sahel may be modulated by intraseasonal variability of the midlatitude flow in the northeastern Atlantic Ocean and Europe, which imposes a zonal mode on the Saharan heat low (Leroux and Hall 2009; Chauvin et al. 2010; Roehrig et al. 2011).

Global and regional climate models have helped increase understanding of the WAM. Several studies have 
analyzed intraseasonal variability of the WAM in global climate models (Lavender and Matthews 2009; Lavender et al. 2010; Pohl and Douville 2011; Roehrig et al. 2013). Lavender and Matthews (2009) found that westwardpropagating Rossby waves were the most important component to trigger West African convective anomalies. Lavender et al. (2010) discovered that soil moisture feedbacks may enhance and organize 15-day oscillations, indicating that the WAM may be capable of producing its own intraseasonal variability. These two studies highlight how uncertain the vitality of the MJO is to intraseasonal variability of the WAM.

Regional climate modeling has played an integral role in simulating the WAM at resolutions finer than most global climate models (Druyan et al. 2010; Nikulin et al. 2012; Sylla et al. 2013), allowing for in-depth interpretation of the WAM and its complicated features. Given the complexity of AEWs (and, in general, the WAM), it is imperative that regional models reproduce key features of this system in order to reliably compare model output to observations or reanalyses. Reliable WAM simulations are important since observations in West Africa are decreasing (e.g., Ali et al. 2005), which limits the utility of observations for understanding this complex region. Vizy and Cook (2002) were the first to study the WAM with a regional climate model adapted from the Penn State University-National Center for Atmospheric Research mesoscale model 5 (PSU-NCAR MM5; Grell et al. 1994). A finer-resolution version of this MM5-adapted model was subsequently utilized in series of studies focused on AEW dynamics (Hsieh and Cook 2005, 2007, 2008). A regional climate model from the MaxPlanck Institute for Meteorology adequately simulated precipitation variability in West Africa over the course of a 25-yr run (Paeth et al. 2005). Several studies have utilized the third generation of the Regional Climate Model (RegCM3) to study the WAM with modest reproduction of key WAM features (Afiesimama et al. 2006; Abiodun et al. 2008; Sylla et al. 2010).

This study utilizes the Weather Research and Forecasting (WRF) Model, specifically the Advanced Research WRF dynamical core (Skamarock and Klemp 2008), to study intraseasonal variability of the WAM. WRF has been widely used as a research tool for investigating the large-scale features of the WAM region (e.g., Flaounas et al. 2011; Gaetani et al. 2010; Nicholson 2013; Noble et al. 2014). These studies have employed horizontal grid spacing on the order of tens of kilometers. Recently, Cook and Vizy (2013) utilized WRF to analyze the rainy season in East Africa. AEW case studies have also been a focus of recent research efforts with WRF (Torn 2010; Wolters et al. 2010; Berry and Thorncroft 2012; Ross et al. 2012). We will use WRF simulations to understand the regulatory processes for intraseasonal variability of the WAM, including the roles of internal variability and remote forcing from the MJO.

The remainder of the paper is organized as follows. In section 2, the WRF configuration is presented, observational data sources are discussed, and three experiments are described to investigate the role of external sources on 30-90-day variability in the WAM. The boreal summer mean of these experiments is scrutinized in section 3 and the 30-90-day variability of these experiments is analyzed in section 4 . We discuss important results and present the conclusions of this study in section 5 .

\section{Model configuration, data, and methodology}

\section{a. Model and data}

We employ the Advanced Research WRF version 3.5.1 with the following configuration: a single domain (no additional nests), 30-km grid spacing, 38 vertical levels (up to $50 \mathrm{hPa}$ ), and 90 -s time step. The model domain, which was chosen specifically to include tropical North Africa and the east Atlantic, spans the region from $10^{\circ} \mathrm{S}$ to $40^{\circ} \mathrm{N}$ and $53^{\circ} \mathrm{W}$ to $42^{\circ} \mathrm{E}$. This domain is wide enough to capture the full life cycle of AEWs, including the potential development into tropical cyclones after propagating into the Atlantic Ocean. However, this domain was carefully chosen to not include 1) the western Indian Ocean, where the MJO initiates, 2) the east Pacific, where a strong amplification of the MJO signal occurs during boreal summer, and 3) the northern midlatitudes, where baroclinic eddies periodically propagate through Europe. Excluding these regions is especially important for the intraseasonal variability sensitivity experiments explained in section 2c. The European Centre for Medium-Range Weather Forecasts (ECMWF) interim reanalysis (ERA-Interim, hereinafter ERA-I; Dee et al. 2011) will be used as the initial and lateral boundary conditions for all WRF experiments. ERA-I has a horizontal resolution of T255 $\left(0.70^{\circ}\right)$ and 60 vertical levels. ERA-I and the 3 B42 rainfall product from the National Aeronautics and Space Administration (NASA) Tropical Rainfall Measurement Mission (TRMM; Kummerow et al. 1998) are used as baselines to validate model output.

\section{b. Model parameterizations}

Parameterizations utilized in this study include the new NASA Goddard longwave and shortwave radiation schemes (Chou and Suarez 1999), the Grell 3D cumulus scheme (Grell and Devenyi 2002), the Mellor-YamadaJanjic (MYJ) planetary boundary layer scheme (Janjic 1994), and the Eta similarity surface scheme 
(Janjic 1994), which is based on Monin and Obukhov (1954). We tested different land surface schemes and microphysics parameterizations using a set of short experiments initialized on 15 May 2001 and run through 31 August 2001. Available computing resources prevented testing of different cumulus parameterizations in these sensitivity experiments. Berry and Thorncroft (2012) showed that the Grell 3D cumulus scheme produces realistic precipitation in AEWs, which motivated the utilization of this scheme in the model configuration.

The two microphysics parameterizations tested were the Thompson scheme (Thompson et al. 2008), which calculates the masses of five water species and the number concentrations for ice and rain, and the WRF single-moment six-class scheme (WSM6; Hong and Lim 2006), which calculates masses for the same five species as the Thompson scheme, but does not calculate any number concentrations. The two land surface models tested in this study were the National Centers for Environmental Prediction-Oregon State UniversityAir Force-Hydrologic Research Laboratory (Noah) land surface model (Ek et al. 2003) and the older Rapid Update Cycle (RUC) scheme (Smirnova et al. 2000), which was shown to perform quite well in the WAM region (Flaounas et al. 2011). Therefore, four sensitivity tests were created from the following parameterization combinations: 1) WSM6/RUC, 2) WSM6/Noah, 3) Thompson/RUC, and 4) Thompson/Noah. Testing revealed that the WSM6/Noah configuration best reproduced AEW activity, the AEJ, and precipitation. Hence, we employed these schemes in the WRF experiments discussed below.

\section{c. WRF simulations}

The WRF experiments described here are designed to determine the extent to which the modulation of AEW activity is explained by external intraseasonal variability, which includes the MJO and MJO-induced equatorial waves. For simplicity, these sensitivity experiments are referred to as "MJO denial tests," which focus on how basic features of the WAM system (i.e., AEWs, precipitation, and the AEJ) and AEW energetics change when external influences on the WAM are removed. In particular, the perturbation kinetic energy (PKE) and perturbation available potential energy (PAPE) budgets are calculated to analyze the energy flows for AEWs simulated in the MJO denial tests. Here, PKE is defined as

$$
\mathrm{PKE}=\frac{\overline{u^{\prime 2}+v^{\prime 2}}}{2},
$$

where $u$ is the zonal wind and $v$ is the meridional wind. The 11-day running mean is represented by $\bar{u}$, while the
TABLE 1. Four PKE source terms investigated in this study. Here $\mathbf{v}$ is the three-dimensional wind $\left(\mathrm{m} \mathrm{s}^{-1}\right.$ or $\left.\mathrm{Pa} \mathrm{s}^{-1}\right), \mathbf{v}_{H}$ is the horizontal wind $\left(\mathrm{m} \mathrm{s}^{-1}\right), \omega$ is the pressure velocity $\left(\mathrm{Pa} \mathrm{s}^{-1}\right), T$ is the air temperature $(\mathrm{K}), p$ is the air pressure $(\mathrm{Pa}), R$ is the specific gas constant of dry air $=287.058 \mathrm{~J} \mathrm{~kg}^{-1} \mathrm{~K}^{-1}, c_{p}$ is the specific heat at constant pressure $=1004 \mathrm{~J} \mathrm{~kg}^{-1} \mathrm{~K}^{-1}, \gamma$ is the inverted static stability, $Q_{1}$ is the apparent heat source, and $\nabla$ is the three-dimensional gradient operator $\left(\mathrm{m}^{-1} \mathrm{~Pa}^{-1}\right) \cdot \bar{X}$ and $X^{\prime}$ represent the 11-day running mean and deviations from the 11-day running mean, respectively.

\begin{tabular}{lll}
\hline \hline \multicolumn{1}{c}{ Creation term } & Symbol & \multicolumn{1}{c}{ Expression } \\
\hline Barotropic energy conversion & $B_{T}$ & $-\overline{\left[\mathbf{v}_{H}^{\prime} \cdot\left(\mathbf{v}^{\prime} \cdot \nabla\right) \overline{\mathbf{v}_{H}}\right.}$ \\
Baroclinic overturning & $C_{\mathrm{pk}}$ & $-\frac{R}{p} \overline{\omega^{\prime} T^{\prime}}$ \\
Baroclinic energy conversion & $B_{C}$ & $-\frac{\gamma c_{p} \overline{\bar{T}} \overline{\mathbf{v}^{\prime} T^{\prime}} \cdot \nabla \bar{T}}{\text { Diabatic PAPE generation }}$ \\
\hline
\end{tabular}

perturbation from the 11-day running mean ("eddy") is represented by $u^{\prime}$. Considering the frequency response function, when $n=11$, the running mean is clearly separated from the 2.5-6-day regime, which describes convectively active AEWs near the AEJ (Wu et al. 2013). Most of the 6-9-day time scale $(\sim 80 \%)$ related to midlatitude interactions with AEWs (Wu et al. 2013) is also removed with the 11-day running mean. The robustness of our results below was tested for different running mean filters, and little sensitivity was produced for values of $n$ between 7 and 15. In addition, $n=11$ excludes 2-week and longer variability, such as the quasi-biweekly zonal dipole (see Mounier et al. 2008). This 11-day running mean was also used to study intraseasonal variability of east Pacific easterly waves (Rydbeck and Maloney 2014).

The PKE and PAPE budgets are derived in AM2014 [see their Eqs. (3) and (4)], who provided a detailed documentation of these budgets for AEWs in ERA-I. These MJO denial tests serve as a modeling extension to the observational energy budget analysis in AM2014. Here, we only consider the four PKE creation terms highlighted in AM2014 (see Table 1). PKE creation terms are computed using a mass-weighted vertical average from 1000 to $200 \mathrm{hPa}$, which is denoted by $\langle X\rangle$.

The MJO denial tests consist of three experiments that are designed to isolate the role of external processes on WAM intraseasonal variability (Fig. 2): a control test with realistic boundary conditions, and two sensitivity tests with filtered lateral boundary conditions and initial conditions. Each simulation spans from 0000 UTC 1 January 2001 to 1800 UTC 31 December 2010, which provide a large sample of intraseasonal variability over 10 boreal summer seasons (i.e., JuneSeptember). The MJO denial control test (C1) uses 

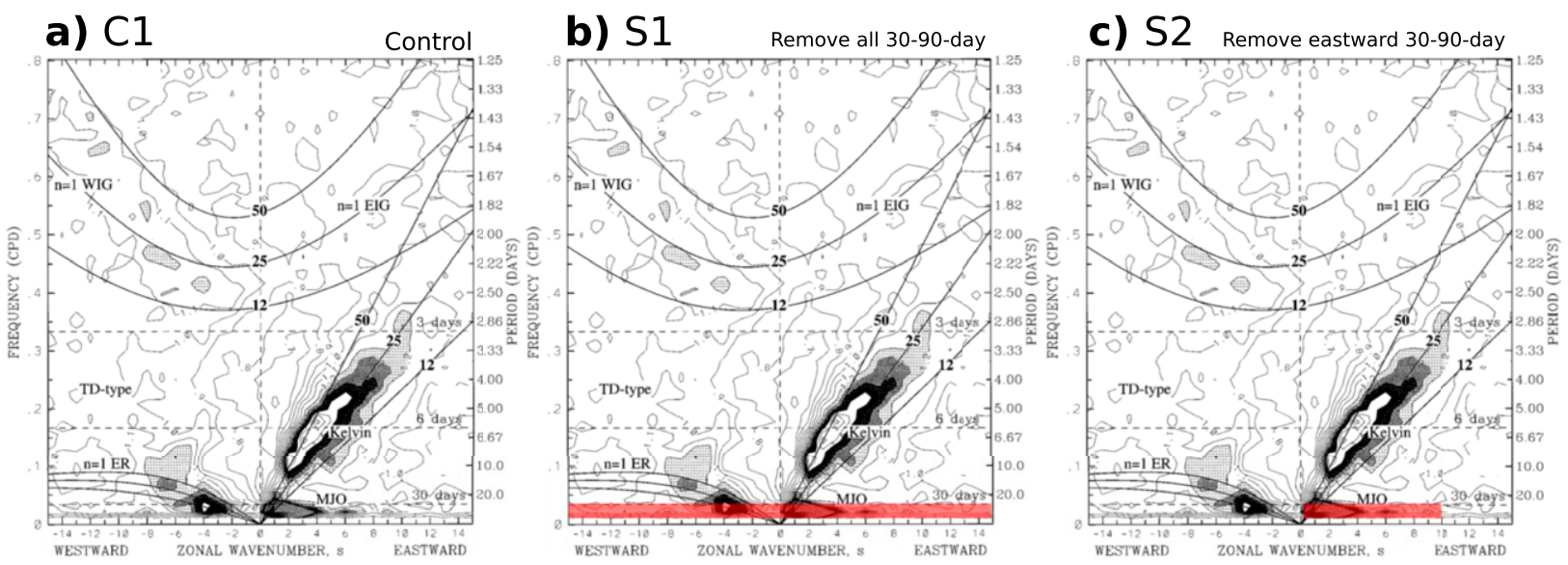

FIG. 2. Wavenumber-frequency filtering of the boundary conditions for the three MJO denial tests, where (a) no filtering is applied (C1), (b), all 30-90-day variability is removed (S1), and (c) only eastward-propagating wavenumbers 0 to 10 are removed from the 30-90-day band (S2). Filtered parts of the wavenumber-frequency domain are represented by red shading. This figure is adapted from Fig. $3 \mathrm{~b}$ in Wheeler and Kiladis (1999).

unfiltered ERA-I data (Fig. 2a) and is representative of 30-90-day WAM variability with the full influence of external forcing. The second and third experiments are sensitivity simulations that filter the ERA-I boundary conditions to different extents. In the first MJO denial sensitivity test (S1), 30-90-day variability is removed for all zonal wavenumbers, which eliminates the influence of all external 30-90-day variability on all model boundaries on the WAM (Fig. 2b). As a result, both eastward and westward propagating influences that project onto MJO time scales are removed from the boundary conditions. In the second MJO denial sensitivity test (S2), 30-90-day variability is only removed for eastward zonal wavenumbers $0-10$, which eliminates only eastward-propagating phenomena, such as Kelvin wave circulations forced by the MJO, from the boundary conditions (Fig. 2c). Westward-propagating influences such as equatorial Rossby waves are retained in S2. For S1 and S2, ERA-I boundary data are filtered through two-dimensional fast Fourier transform analysis. A boxcar-type filter is applied to the data once they have been converted to wavenumber-frequency space. The 30-90-day filter is applied to the entire ERA-I boundary field, so that influences from the MJO and other external large-scale phenomena (e.g., Indian monsoon, midlatitude variability) are effectively removed.

The power of most large-scale equatorial Rossby waves falls within the 30-90-day band. However, the power of Kelvin waves extends into much shorter time scales and smaller zonal wavelengths, which suggests that these equatorial waves are incompletely filtered by our method. While this is true, a distinction is drawn here between convectively coupled Kelvin waves and the dry Kelvin wave feature that is forced by MJO heating and establishes rapidly through propagation regulated by dry dynamics (e.g., Sobel and Maloney 2012). Here, the dry Kelvin wave mode characteristic of the Gill (1980) model and forced as a quasi-steady response to the east of MJO convection is removed via filtering in S1 and S2. While previous work showed a relationship between convectively coupled Kelvin waves and AEWs (e.g., Ventrice and Thorncroft 2013), the time scales of these phenomena are much shorter than the large-scale feature associated with the MJO and are not of interest to this study.

To aid in the analysis of these MJO denial tests, several methods from AM2014 were employed. For each MJO denial test, the 30-90-day AEW activity in West Africa is assessed by a PKE index, calculated by areaaveraging 30-90-day $700-\mathrm{hPa} \mathrm{PKE}$ in a $20^{\circ} \times 10^{\circ}$ region located in West Africa. The longitude of this region was fixed at $20^{\circ} \mathrm{W}-0^{\circ}$ and a $10^{\circ}$ latitude range was adjusted for each test to account for meridional shifts in highamplitude, boreal summer mean 700-hPa PKE. The PKE index region for each respective MJO simulation is given in section 4a. Since AEW activity is concentrated in boreal summer, the analysis focuses on June to September. Significant maxima $(>1 \sigma)$ are identified in each PKE index during boreal summer, called "positive PKE events," and lead/lag composites are created to study the evolution of PKE and other relevant fields for all positive PKE events. In particular, these positive PKE event composites help describe the intraseasonal evolution of key WAM system features and AEW energetics. Power spectra were produced for the PKE indices by averaging the spectrum of each summer segment. The corresponding red noise spectra were calculated using a Markov model (e.g., Gilman et al. 1963) based 


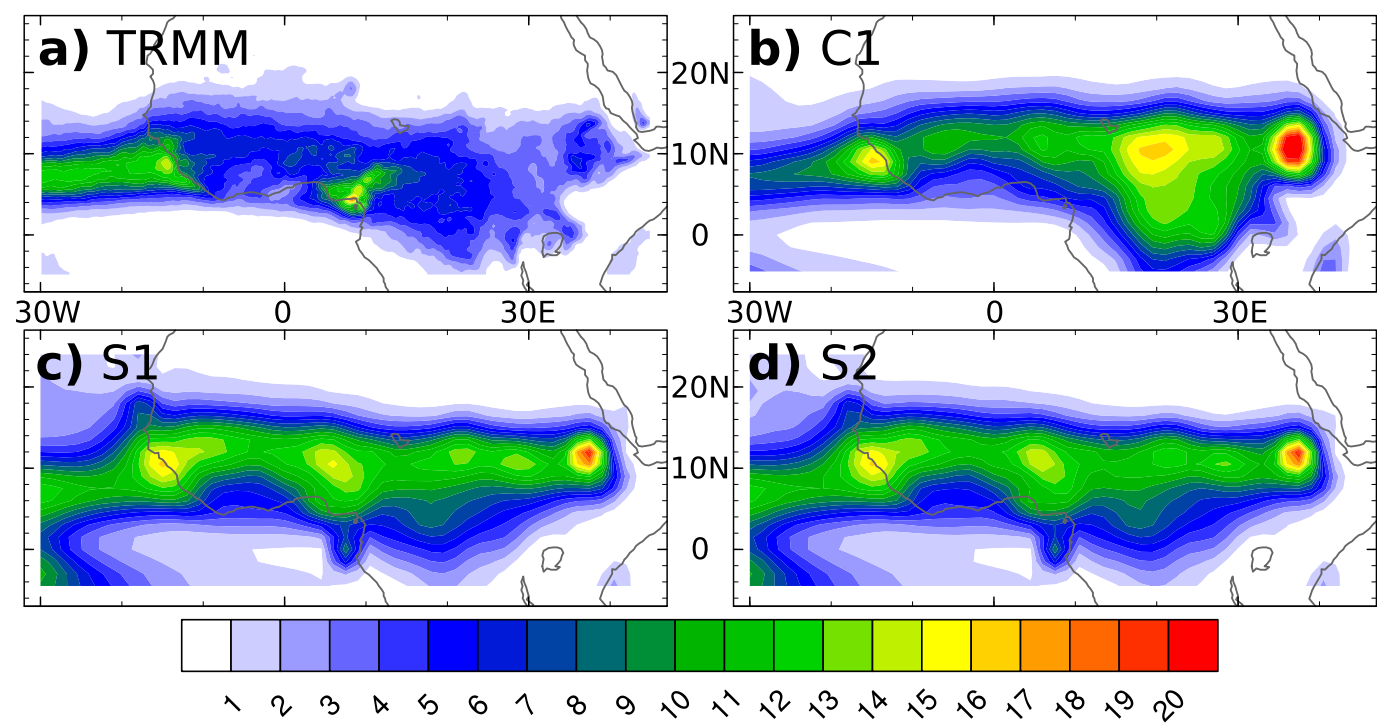

FIG. 3. June-August mean precipitation rate $\left(\mathrm{mm} \mathrm{day}^{-1}\right)$ from (a) TRMM, (b) C1, (c) S1, and (d) S2.

on a representative lag-1 autocorrelation ${ }^{1}$ for all seasons. A Student's $t$ test was employed to highlight the null hypothesis that anomalies are not statistically different than zero at the $95 \%$ confidence level.

\section{Boreal summer mean results}

\section{a. WAM system}

The boreal summer mean WAM is analyzed for each of the MJO simulations. When averaged over 10 boreal summer seasons, the basic features of the WAM system (e.g., precipitation, AEJ, and AEWs) are qualitatively similar in the control and two sensitivity tests. For example, all three tests produce similar precipitation rates in June-September (Figs. 3b-d), with local maxima at the West African coast, near the Cameroon highlands $\left(10^{\circ} \mathrm{E}\right)$, and in the Ethiopian highlands $\left(40^{\circ} \mathrm{E}\right)$. These modeled precipitation maxima are roughly in the same longitudinal locations as observed by TRMM, except shifted north by $\sim 2^{\circ}$ (Fig. 3a). All three experiments produce too much precipitation over land when compared with TRMM. In fact, the model produces nearly $2000 \mathrm{~mm}(2500 \mathrm{~mm})$ of excess precipitation to the Sahel (Ethiopian highlands) over the course of a boreal summer season. However, TRMM is not a perfect baseline

\footnotetext{
${ }^{1}$ To calculate, 1 ) compute the lag-1 (i.e., one-day lag) autocorrelation for each boreal summer season, 2) perform a Fisher $z$ transformation to approximate normal distribution (Fisher 1915, 1921), 3) average the Fisher $z$ value over all boreal summer seasons, and, 4) transform back from Fisher $z$ to attain the representative lag-1 autocorrelation.
}

over North Africa, considering that it is corrected by rain gauges and this region has actually seen a decline in such observations (Ali et al. 2005; Tian et al. 2007). In general, TRMM has been known to underestimate most rainfall rates over land due to issues predicting emissivity (Tian et al. 2007). Although $\mathrm{C} 1, \mathrm{~S} 1$, and S2 produce comparable precipitation in this region, key differences exist. For example, $\mathrm{C} 1$ rainfall is lower than $\mathrm{S} 1$ or $\mathrm{S} 2$ between the Cameroon highlands and the West African coast. On the other hand, near the Ethiopian highlands, the area of precipitation greater than $20 \mathrm{~mm} \mathrm{day}^{-1}$ is larger in $\mathrm{C} 1$ than in S1/S2.

The mean precipitation maps for $\mathrm{S} 1$ and $\mathrm{S} 2$ are nearly identical, which downplays the importance of westwardpropagating 30-90-day disturbances (e.g., equatorial Rossby waves) in the simulation of the WAM. In fact, the strong similarity of $\mathrm{S} 1$ and $\mathrm{S} 2$ is a robust result for the remainder of this study, including for both general WAM fields and AEW energetics. Consequently, the remaining analyses will focus only on $\mathrm{C} 1$ and $\mathrm{S} 1$ to avoid redundancy. The modeling results presented here are in contention with previous studies that have emphasized the importance of both MJO-induced equatorial Kelvin and Rossby waves for modulating WAM intraseasonal variability (e.g., Matthews 2004; Lavender and Matthews 2009; Janicot et al. 2011; Alaka and Maloney 2012). The similarity of S1 and $\mathrm{S} 2$ suggests that westward-propagating disturbances on intraseasonal time scales have only modest influence on WAM intraseasonal variability, at least in this model.

The observed mean zonal wind state of the WAM is documented by an ERA-I cross section spanning $0^{\circ}-25^{\circ} \mathrm{N}$ and $1000-200 \mathrm{hPa}$ (Fig. 4a). The zonal wind 
a) ERA-I

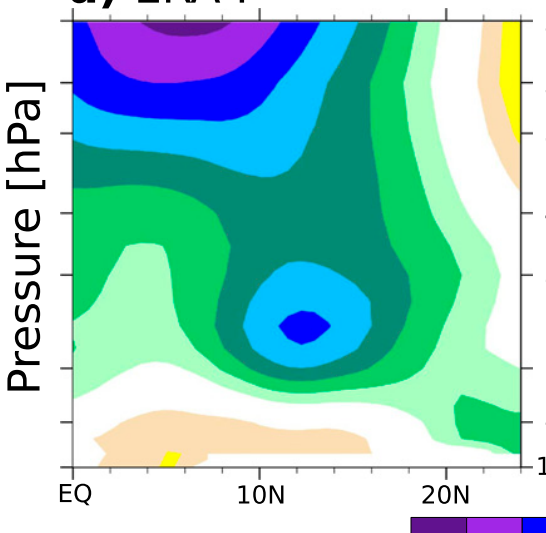

b) $\mathrm{C} 1$

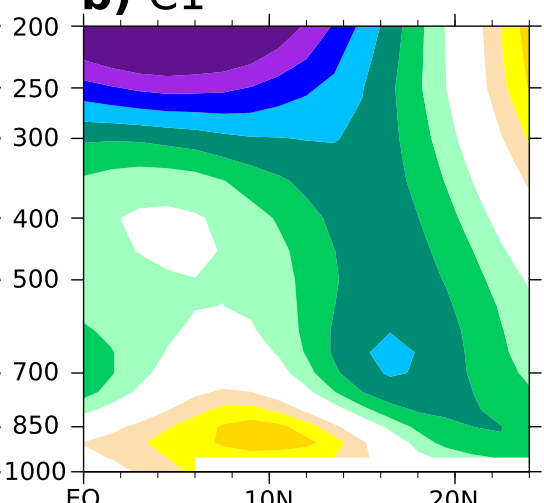

c) $\mathrm{S} 1$

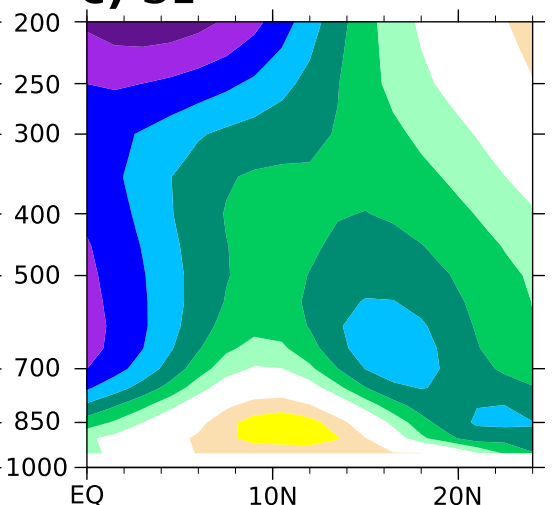

$\begin{array}{lllllllllllllll}-14 & -12 & -10 & -8 & -6 & -4 & -2 & 0 & 2 & 4 & 6 & 8 & 10 & 12 & 14\end{array}$

FIG. 4. Latitude-pressure cross sections of the June-September mean zonal wind (m s ${ }^{-1}$ ) for (a) ERA-I, (b) C1, and (c) S1. Cross sections are averaged from $0^{\circ}$ to $20^{\circ} \mathrm{E}$.

structure of the AEJ is reproduced qualitatively in the model (Fig. 4b). Minor differences exist in the $\mathrm{C} 1 \mathrm{AEJ}$; it is $2 \mathrm{~m} \mathrm{~s}^{-1}$ weaker, $4^{\circ}$ farther north, and $50 \mathrm{hPa}$ lower in the atmosphere than ERA-I. Also, the monsoon westerlies, centered near $10^{\circ} \mathrm{N}$, extend higher in the troposphere and are $4 \mathrm{~m} \mathrm{~s}^{-1}$ faster in $\mathrm{C} 1$, increasing the meridional momentum gradient and contributing to amplified PKE within AEWs. The S1 AEJ is generally similar to that in C1 and ERA-I (Fig. 4c), except that it is $1 \mathrm{~m} \mathrm{~s}^{-1}$ stronger and closer to the observed amplitude. It is worth noting that $\mathrm{S} 1$ exhibits mean easterlies $\left(<-12 \mathrm{~m} \mathrm{~s}^{-1}\right)$ near the equator in the lower-to-middle troposphere (i.e., between 800 and $500 \mathrm{hPa}$ ) that are faster than in $\mathrm{C} 1$ or ERA-I. These strong easterlies represent a momentum imbalance that likely results from the removal of eastward propagating equatorial disturbances such as Kelvin waves. It is unclear why such eastward propagating disturbances are important to the maintenance of the low-level equatorial flow in the WAM. This is a topic for future research. Given similarity in intraseasonal variability in S1 relative to $\mathrm{C} 1$ (shown below), it does not appear that this easterly bias is of much consequence for regulation of intraseasonal variability over the WAM region.

$\mathrm{C} 1$ and $\mathrm{S} 1$ exhibit higher boreal summer mean 700-hPa PKE than ERA-I, especially over land in the WAM region (Fig. 5). These higher PKE values may be linked to stronger surface westerlies and PKE maximum that is lower in the troposphere, which would tend to increase the horizontal and vertical momentum gradients near $700 \mathrm{hPa}$. In ERA-I, $700 \mathrm{hPa}$ PKE to the south of $20^{\circ} \mathrm{N}$ steadily increases to the west until $15^{\circ}-20^{\circ} \mathrm{W}$, with a value of $14 \mathrm{~m}^{2} \mathrm{~s}^{-2}$ near Dakar, Senegal $\left(15^{\circ} \mathrm{N}, 18^{\circ} \mathrm{W}\right)$ (Fig. 5a). The 700-hPa PKE maximum, which is located farther north along the West African coast, is not a distinct AEW signal and is therefore not further discussed. Offshore 700-hPa PKE amplitudes are comparable in both ERA-I and C1. However, C1 exhibits higher PKE amplitudes over land, including a maximum near Lake Chad $\left(13^{\circ} \mathrm{N}, 14^{\circ} \mathrm{W}\right)$, where it is 4 times greater than ERA-I (Fig. 5b). In S1, the pattern of 700-hPa PKE
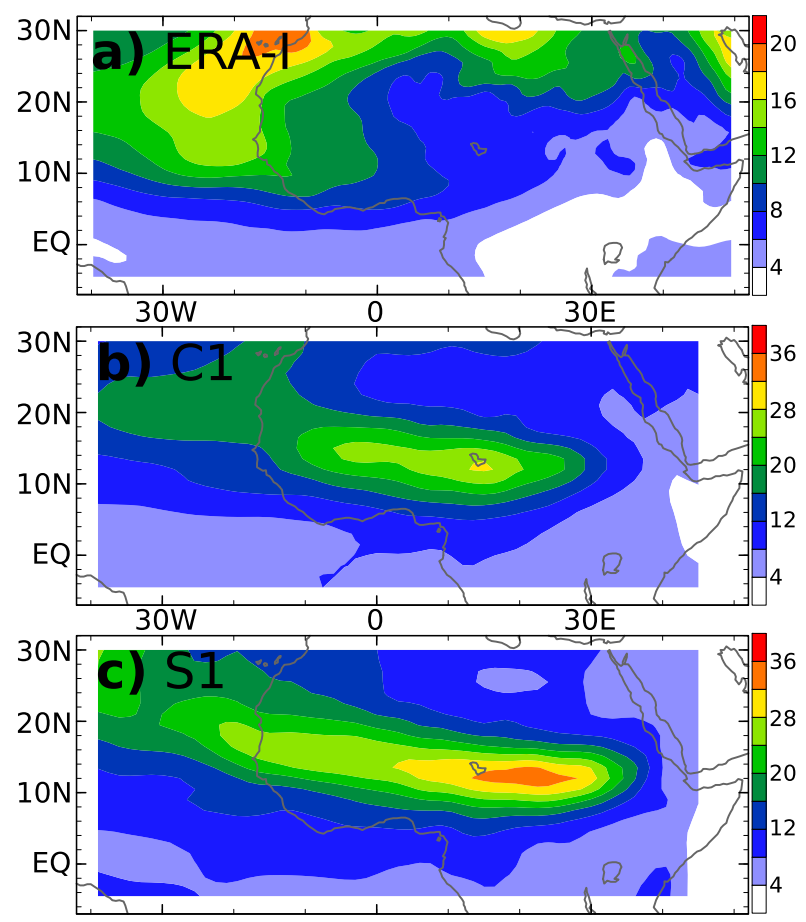

FIG. 5. June-September mean 700-hPa PKE $\left(\mathrm{m}^{2} \mathrm{~s}^{-2}\right)$ for (a) ERA-I, (b) C1, and (c) S1. The shading interval is $2 \mathrm{~m}^{2} \mathrm{~s}^{-2}$ in (a) and $4 \mathrm{~m}^{2} \mathrm{~s}^{-2}$ in (b) and (c). 

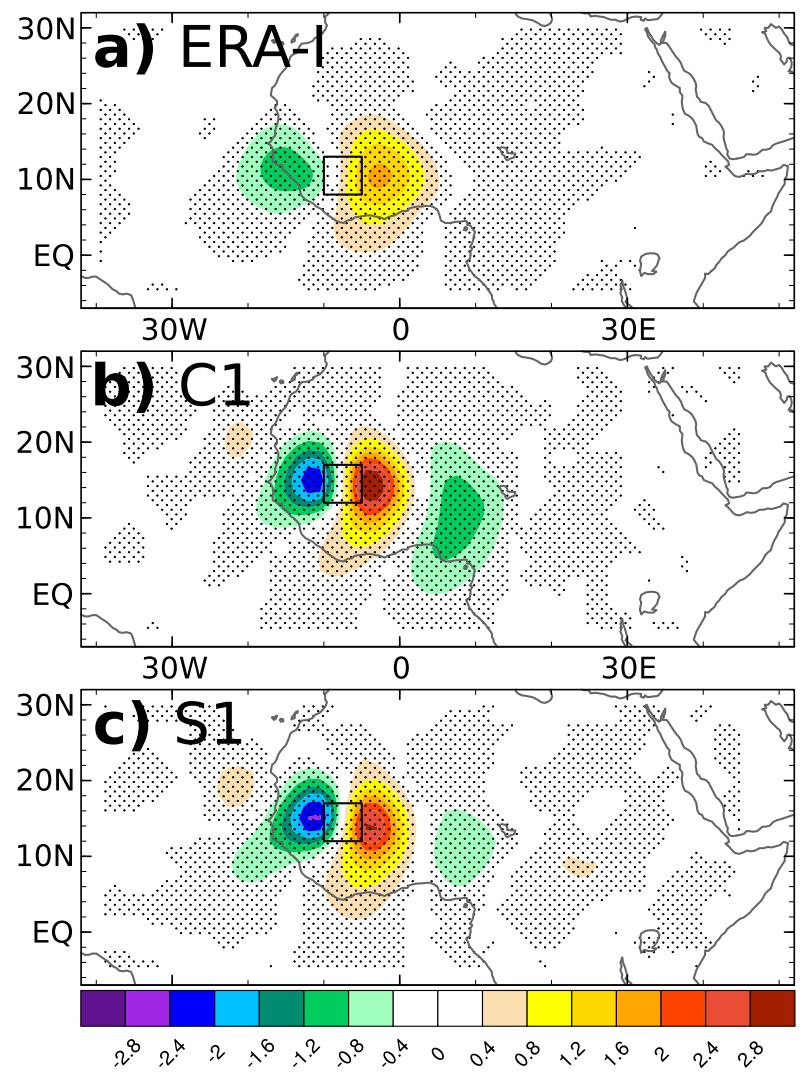

FIG. 6. Eddy 700-hPa meridional wind regressed against areaaveraged eddy $700-\mathrm{hPa}$ vorticity $\left(\mathrm{m} \mathrm{s}^{-1} \mathrm{~s}\right)$ for (a) $\mathrm{C} 1$ and (b) S1. Stippling represents values that exceed the $95 \%$ confidence threshold.

is stronger and farther east than $\mathrm{C} 1$, with a maximum of $34 \mathrm{~m}^{2} \mathrm{~s}^{-2}$ to the east of Lake Chad. PKE was expected to be higher in S1 given that the AEJ amplitude was stronger than in $\mathrm{C} 1$. In $\mathrm{C} 1$ and $\mathrm{S} 1$, the pattern of 700-hPa PKE strongly resembles AEW tracks in this region.

Despite the higher PKE values in both $\mathrm{C} 1$ and S1, both experiments produce an AEW structure similar to that in ERA-I (Fig. 6). AEW structure is measured by regressing eddy ${ }^{2} 700-\mathrm{hPa}$ meridional wind against eddy $700-\mathrm{hPa}$ relative vorticity averaged in a $5^{\circ} \times 5^{\circ}$ West African box. This West African box is shifted meridionally in each experiment to coincide with the latitude of highest West African 700-hPa PKE (see Fig. 5). These boxes are shown in Fig. 6. In ERA-I, AEWs span $\sim 2500 \mathrm{~km}$ in the zonal direction, with meridional wind anomaly amplitudes reaching greater than $1.6 \mathrm{~m} \mathrm{~s}^{-1}$ to the east of the AEW center (Fig. 6a). In C1 and S1, the spatial structure of AEW activity is generally consistent

\footnotetext{
2 "Eddy" refers to the perturbation from the 11-day running mean.
}

with ERA-I. However, in the simulations, meridional wind anomalies are stronger $\left(>2.8 \mathrm{~m} \mathrm{~s}^{-1}\right)$ and the zonal wavelength is shorter $(\sim 2000 \mathrm{~km})$. In all simulations, the classic southwest-northeast tilt to the south of the AEJ (see Fig. 4) is clearly observed, with opposite tilt to the north of the AEJ (e.g., Kiladis et al. 2006). It is hypothesized that these stronger AEWs are associated with a sharper meridional momentum gradient, which would enhance barotropic energy conversions in the WAM. Accordingly, boreal summer mean energy conversions are investigated in further detail below.

\section{b. AEW energetics}

Following the methods of AM2014, boreal summer mean AEW energetics are investigated for each simulation. These simulated PKE and PAPE budget terms, which are presented as vertically averaged horizontal maps (Figs. 7 and 8), are qualitatively similar to ERA-I results in AM2014 (their Fig. 4) and other previous studies (e.g., Lau and Lau 1992; Diedhiou et al. 2002; Hsieh and Cook 2007). In particular, we focus on four energy conversion terms that are crucial for PKE creation $^{3}$ : barotropic energy conversion $\left(B_{T}\right)$, baroclinic energy conversion $\left(B_{C}\right)$, diabatic PAPE generation $\left(Q_{T}\right)$, and how these latter two terms are converted to PKE by baroclinic overturning $\left(C_{\mathrm{pk}}\right)$. In $\mathrm{C} 1$ and $\mathrm{S} 1,700-\mathrm{hPa}$ PKE amplitudes across tropical North Africa are larger than ERA-I PKE at the same level by at least a factor of 3 (see Fig. 5). This excess PKE reflects stronger AEW activity in WRF than in ERA-I and requires stronger PKE creation terms. In addition, the 700-hPa PKE maximum is located farther east than in ERA-I in both simulations, suggestive of stronger PKE creation in East Africa. Despite the removal of 30-90-day variability, the boreal summer mean PKE and PAPE budgets computed from $\mathrm{S} 1$ output generally resemble the $\mathrm{C} 1$ results. The model biases described below do not affect conclusions drawn from subseasonal variability, detailed in the next section.

Since barotropic energy conversions $\left(B_{T} ;\right.$ Figs. $7 \mathrm{a}$ and 8a) convert mean kinetic energy (e.g., AEJ flow) into PKE in regions of strong horizontal wind shear, the amplitude of $B_{T}$ is closely linked to the AEJ structure and amplitude. Unlike in ERA-I, $\left\langle B_{T}\right\rangle$ is strongest in East Africa in $\mathrm{C} 1$ and $\mathrm{S} 1$. In $\mathrm{C} 1$, a local $\left\langle B_{T}\right\rangle$ maximum is centered on Lake Chad $\left(12^{\circ} \mathrm{E}\right)$ that is a factor of 2 larger than the east Atlantic maximum observed in ERA-I (see Fig. $\mathrm{S}^{4}$ in the online supplemental material). Despite the smaller AEJ amplitudes, which are weaker

\footnotetext{
${ }^{3}$ See Table 1 for mathematical expressions.

${ }^{4}$ Note that Fig. $\mathrm{S} 1$ is distinct from the sensitivity experiment $\mathrm{S} 1$.
} 

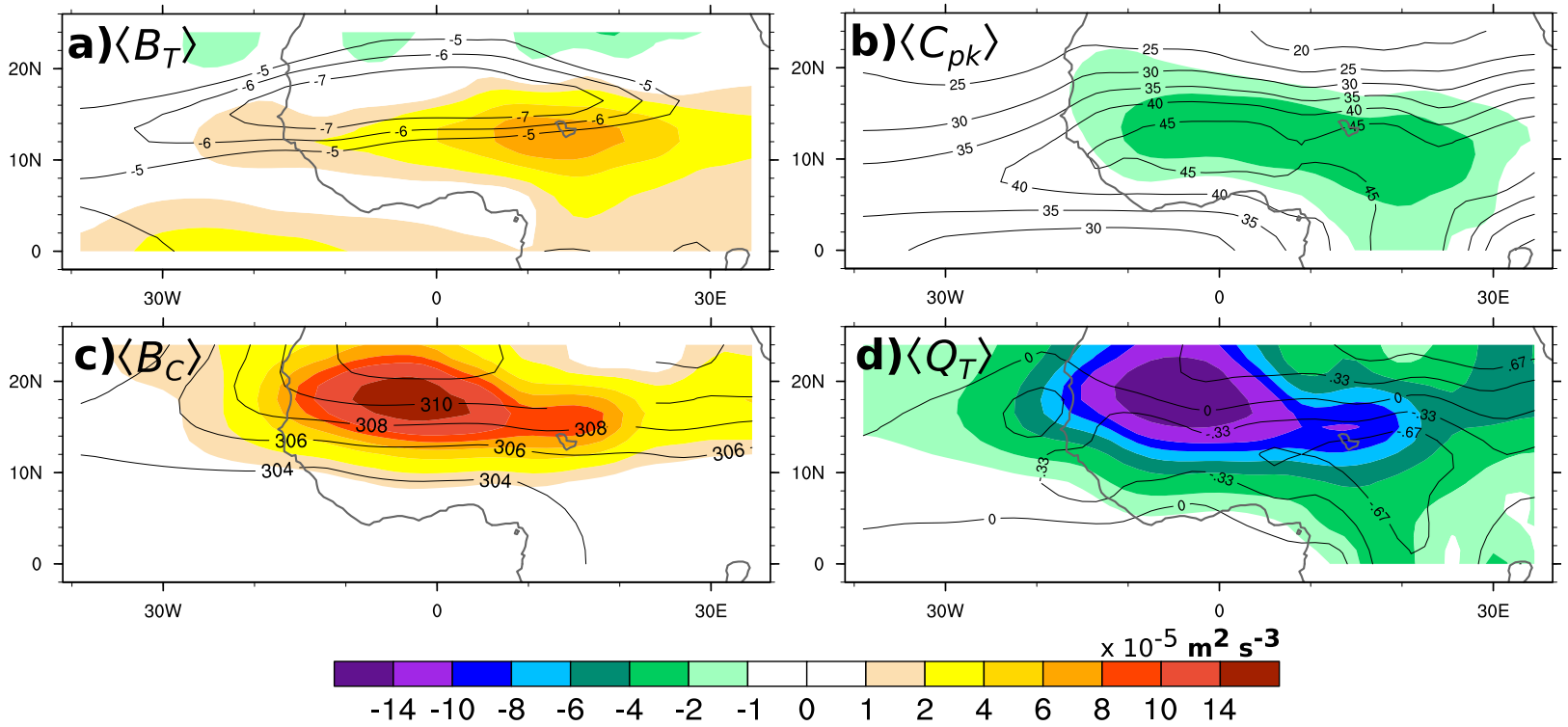

FIG. 7. Vertically integrated PKE and PAPE budget terms $\left(\mathrm{m}^{2} \mathrm{~s}^{-3}\right)$ and supporting fields averaged in June-September from C1. Shown are (a) barotropic energy conversion $\left(B_{T}\right)$ and $650-\mathrm{hPa}$ zonal wind (contours; $\mathrm{m} \mathrm{s}^{-1}$ ), (b) baroclinic overturning $\left(C_{\mathrm{pk}}\right)$ and total precipitable water (contours; mm), (c) baroclinic energy conversion $\left(B_{C}\right)$ and 850-hPa potential temperature (contours; K), and (d) diabatic generation of PAPE $\left(Q_{T}\right)$ and the mean apparent heating rate (contours; $\mathrm{K}_{\text {day }}{ }^{-1}$ ).

by $3-4 \mathrm{~m} \mathrm{~s}^{-1}$, monsoon westerlies on the southern flank of the AEJ in East Africa create a sharp momentum gradient near Lake Chad and leads to higher $\left\langle B_{T}\right\rangle$ amplitudes (see Fig. 4b). In S1, a local $\left\langle B_{T}\right\rangle$ maximum is centered even farther east $\left(22^{\circ} \mathrm{E}\right)$ and is a factor of 2 larger than the $\mathrm{C} 1$ maximum near Lake Chad. The S1 AEJ is stronger than the $\mathrm{C} 1 \mathrm{AEJ}$, contributing to higher amplitudes of $\left\langle B_{T}\right\rangle$, especially in East Africa. In fact, the
$\mathrm{S} 1 \mathrm{AEJ}$ is at least $1 \mathrm{~ms}^{-1}$ faster for most of the zonal extent of North Africa, which is reflected by $\left\langle B_{T}\right\rangle$. Equatorial easterly wind biases were noted in S1 compared to $\mathrm{C} 1$ (Fig. 4), although it is not clear how these biases relate to the $\left\langle B_{T}\right\rangle$ signal. Despite similarities to ERA-I, modeled $\left\langle B_{T}\right\rangle$ 1) does not appear to assist wave disturbances on the northern side of the AEJ and 2) diminishes in the east Atlantic relative to ERA-I (Fig. S1).
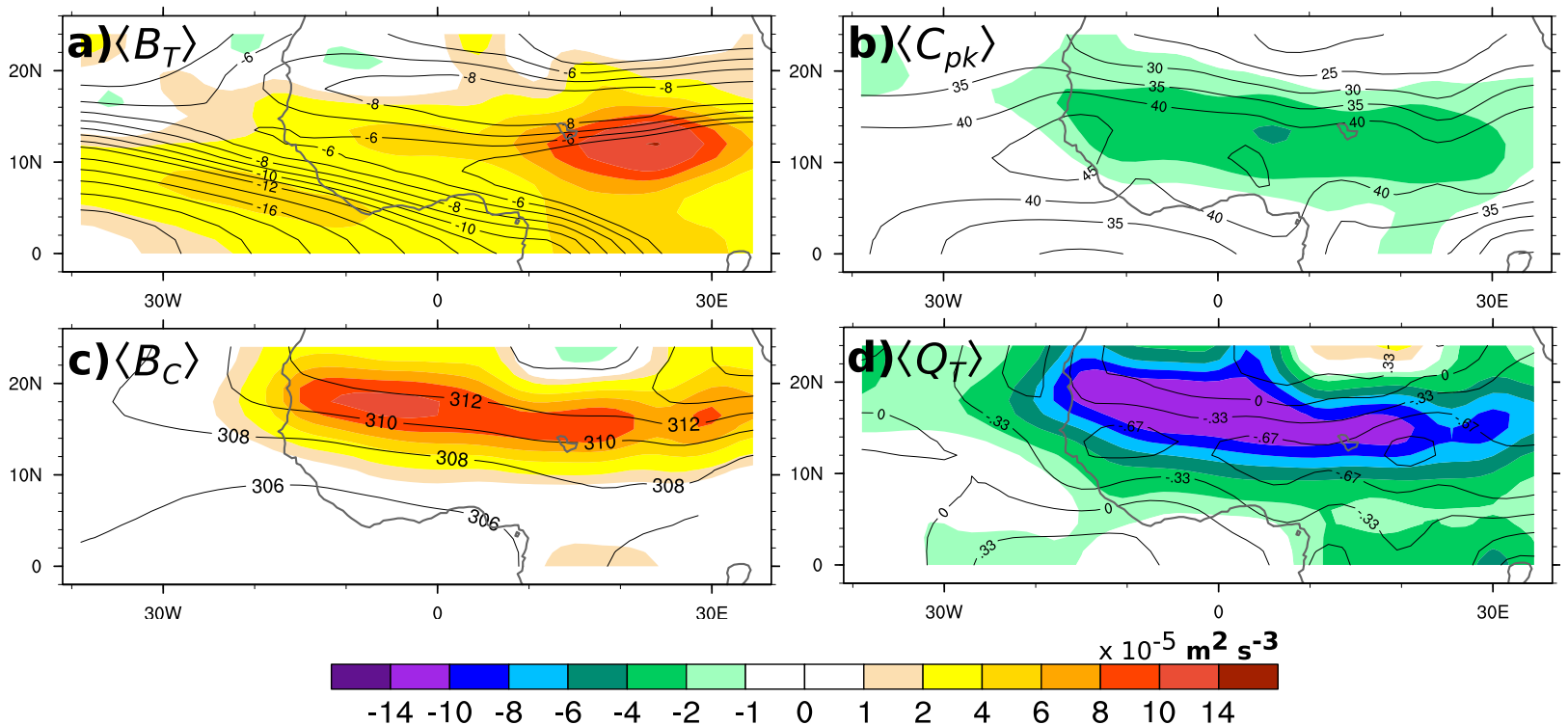

FIG. 8. As in Fig. 7, but for S1. 

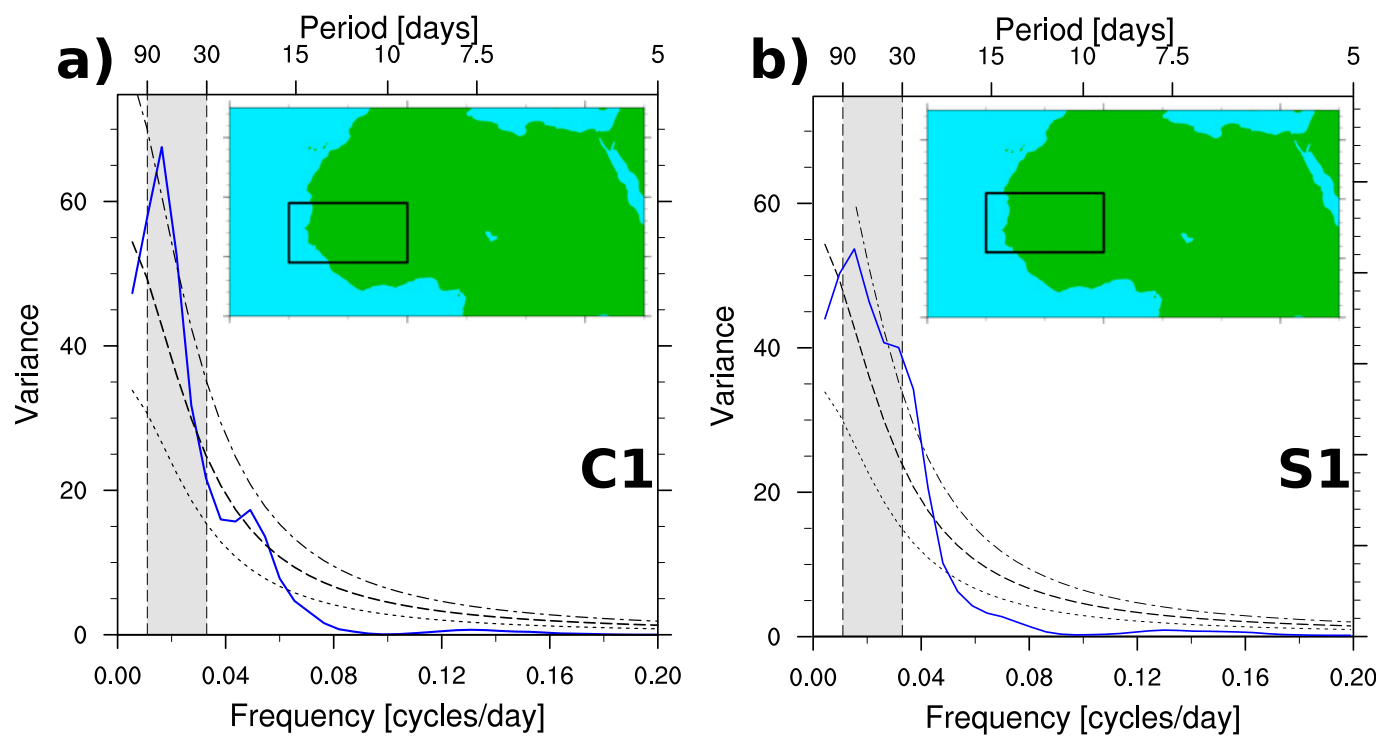

FIG. 9. Power spectra averaged in June-September for $700 \mathrm{hPa}$ PKE $\left(\mathrm{m}^{2} \mathrm{~s}^{-2}\right)$ for (a) $\mathrm{C} 1$ and (b) S1. Map insets show the area where spectra are computed. The associated red noise spectrum with $95 \%$ confidence bounds is given by the black curves. The gray shading represents the 30-90-day band.

Baroclinic energy conversions $\left(B_{C} ;\right.$ Figs. $7 \mathrm{c}$ and $\left.8 \mathrm{c}\right)$ straddle the strongest low-level potential temperature gradient in the model, with a local maximum in subSaharan West Africa. The meridional temperature gradient is $\sim 50 \%$ weaker in $\mathrm{C} 1\left(0.06 \mathrm{~K} \mathrm{~km}^{-1}\right)$ than in ERA-I $\left(0.1 \mathrm{~K} \mathrm{~km}^{-1}\right.$; see Fig. S1), which results in $\left\langle B_{C}\right\rangle$ amplitudes that are about a factor of 2 smaller in $\mathrm{C} 1$ than in reanalysis data. In $\mathrm{S} 1$, the meridional temperature gradient is even weaker $\left(0.04 \mathrm{~K} \mathrm{~km}^{-1}\right)$, contributing to even smaller $\left\langle B_{C}\right\rangle$ amplitudes (by a factor of 3 ). The further reduction of the meridional temperature gradient in $\mathrm{S} 1$ is attributed to $850-\mathrm{hPa}$ potential temperatures that are $\sim 2 \mathrm{~K}$ warmer in the Gulf of Guinea (Fig. $8 \mathrm{c}$ ). It is interesting to note that $\mathrm{S} 1$, which has higher $700-\mathrm{hPa}$ PKE than $\mathrm{C} 1$, also has greater $\left\langle B_{T}\right\rangle$ amplitude. Perhaps of more importance to $700-\mathrm{hPa} \mathrm{PKE}$ is the greater zonal extent of these energy conversions in $\mathrm{S} 1$.

In the model results, the destruction of PAPE by $Q_{T}$ outweighs the creation of PAPE by $B_{C}$ (Figs. 7d and 8d). As expected, this PAPE budget imbalance is reflected in $C_{\mathrm{pk}}$, which destroys PKE in C1 rather than creates it (see Figs. $7 \mathrm{~b}$ and $8 \mathrm{~b}$ ). While $\left\langle Q_{T}\right\rangle$ magnitudes were realistic in $\mathrm{C} 1$, they were more than $4 \mathrm{~m}^{2} \mathrm{~s}^{-3}$ weaker in S1. AM2014 describe mechanisms for negative $Q_{T}$ in this region. Essentially, diabatic heating is suppressed in the warm, dry northerly flow from the Sahara Desert, and, in the opposite sense, in the cool, moist flow from the Gulf of Guinea, creating a negative correlation between apparent heat source and temperature anomalies. Upon closer examination, mid- to upper-level temperature anomalies are poorly simulated in the WAM region, leading to errors in $\left\langle Q_{T}\right\rangle$.
Consistent with ERA-I, baroclinic overturning $\left(C_{\mathrm{pk}}\right.$; Figs. $7 \mathrm{~b}$ and $8 \mathrm{~b}$ ) is strongly anticorrelated with geopotential flux convergence ( $\phi_{\mathrm{FC}}$; not shown), especially in the upper troposphere, a relationship in the tropics noted by Lau and Lau (1992). However, as previously noted, negative $C_{\mathrm{pk}}$ in $\mathrm{C} 1$ and $\mathrm{S} 1$, indicating destruction of PKE, is reversed from ERA-I (Fig. S1). In general, the sign reversal of $C_{\mathrm{pk}}$ in C1/S1 compared to ERA-I can be attributed to differences in the PAPE budget relative to ERA-I. In particular, PAPE generation (via $Q_{T}$ and $B_{C}$ ) is converted to PKE through $C_{\mathrm{pk}}$ (Lau and Lau 1992; Hsieh and Cook 2007; AM2014). Effectively, negative $\left\langle C_{\mathrm{pk}}\right\rangle$ suggests that PKE may be dominantly created by $B_{T}$ in both experiments.

\section{Intraseasonal variability results}

\section{a. 30-90-day WAM system}

Intraseasonal 700-hPa PKE indices are created in West Africa for each simulation. A PKE index is produced for each simulation based on the latitudinal location of the strongest West African mean $700-\mathrm{hPa}$ PKE. For consistency, each PKE index spans $20^{\circ} \mathrm{W}$ to $0^{\circ} \mathrm{E}$ with a $10^{\circ}$ latitudinal range that best captures the mean PKE (Fig. 6). For $\mathrm{C} 1$, the box includes $10^{\circ}-20^{\circ} \mathrm{N}$ (Fig. 9a). In S1, the PKE index box is shifted north to include $11^{\circ}-21^{\circ} \mathrm{N}$ (Fig. 9b).

A robust result across these WRF simulations is the presence of strong AEW activity on intraseasonal time scales (Fig. 9). In C1, the significant 700-hPa PKE index 


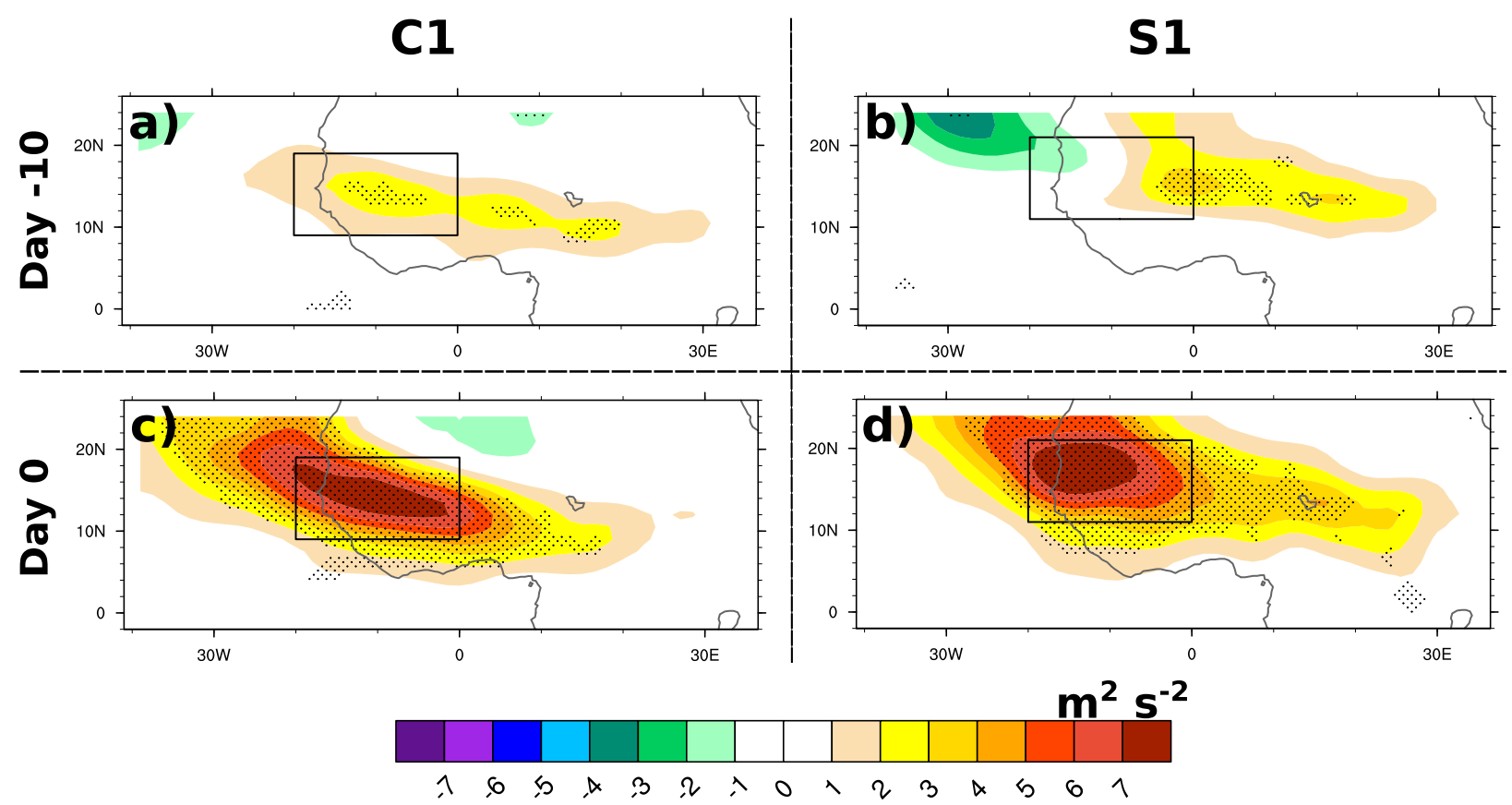

FIG. 10. Lead-lag maps of 30-90-day $700 \mathrm{hPa}$ PKE anomalies $\left(\mathrm{m}^{2} \mathrm{~s}^{-2}\right)$ for June-September composited before (day -10) and during (day 0) positive PKE events in MJO denial tests. Shown are (a) C1 day -10, (b) S1 day -10, (c) C1 day 0, and (d) S1 day 0. Stippling represents significance at the $95 \%$ confidence level.

spectral peak is evidence that, with unfiltered boundary conditions, WRF can reasonably reproduce intraseasonal variability in West African AEW activity (Fig. 9a). The 30-90-day power of AEW activity in $\mathrm{C} 1$ is consistent with that found in ERA-I (Fig. S2). ${ }^{5}$ The S1 experiment features a 30-90-day spectral peak that is also located near 60 days but is reduced in amplitude by $\sim 15 \%$ in comparison to $\mathrm{C} 1$. Despite having lower power near 60 days, $\mathrm{S} 1$ features higher power at shorter intraseasonal time scales (Fig. 9b), which likely explains why the maximum intraseasonal variance is larger for S1 than $\mathrm{C} 1$ in East Africa and the east Atlantic (Fig. 6). The S1 results suggest a faster oscillation in the WAM without the large-scale pacing provided by the MJO. The similar spectral behavior between S1 and S2 (not shown) suggests that intraseasonal Kelvin waves spawned by MJO heating appear to dictate a stricter time scale for WAM variability and may be important for pacing the intraseasonal oscillation in this region. Without MJO forcing, intraseasonal PKE power becomes more diffuse, spreading across a broader range of intraseasonal time scales (Fig. 9b). For example, 30-day power in $\mathrm{S} 1$ is larger than the 30-day power in $\mathrm{C} 1$ by a factor of 2. In summary, the results of Fig. 9 indicate that even in the absence of 30-90-day input from the

\footnotetext{
${ }^{5}$ Note that Fig. S2 is distinct from the sensitivity experiment S2.
}

boundary conditions, WRF still produces strong power at intraseasonal frequencies. In other words, these results suggest that intraseasonal variability of West African AEW activity may be internally generated, which is consistent with the previous result from AM2014 that the MJO index explains only $10 \%$ of the intraseasonal variance of West African PKE.

The MJO simulations produce qualitatively similar composites of $700-\mathrm{hPa} \mathrm{PKE}_{30-90}$ anomalies, with West African maxima exceeding $7 \mathrm{~m}^{2} \mathrm{~s}^{-2}$ (Figs. 10 and 11). AEW activity has a more dominant column-integrated presence than in ERA-I (Fig. S3), as supported by vertically averaged PKE in excess of $3 \mathrm{~m}^{2} \mathrm{~s}^{-2}$ in the WRF simulations. Simulated $700-\mathrm{hPa} \mathrm{PKE}_{30-90}$ anomalies are present in East Africa at least 10 days prior to positive PKE events (Figs. 10a,b), consistent with AM2014. This tendency for East Africa to lead is more notable in S1 than in $\mathrm{C} 1$, as will be shown in Fig. 11. Although the magnitude of West African $700-\mathrm{hPa} \mathrm{PKE}_{30-90}$ anomalies is very similar in these experiments, the elongated maximum in $\mathrm{C} 1$ looks more like reanalysis data than S1 (Fig. S3). Both experiments appear to limit the westward propagation of AEWs after entering the east Atlantic, with $700-\mathrm{hPa}$ $\mathrm{PKE}_{30-90}$ anomalies reflective of disturbances that gain latitude more quickly than in observations and reanalyses.

Consistent with the spectral analysis reported earlier, 700-hPa $\mathrm{PKE}_{30-90}$ anomalies in the $\mathrm{S} 1$ experiment exhibit a somewhat shorter period for intraseasonal 
a) $\mathrm{C1}$

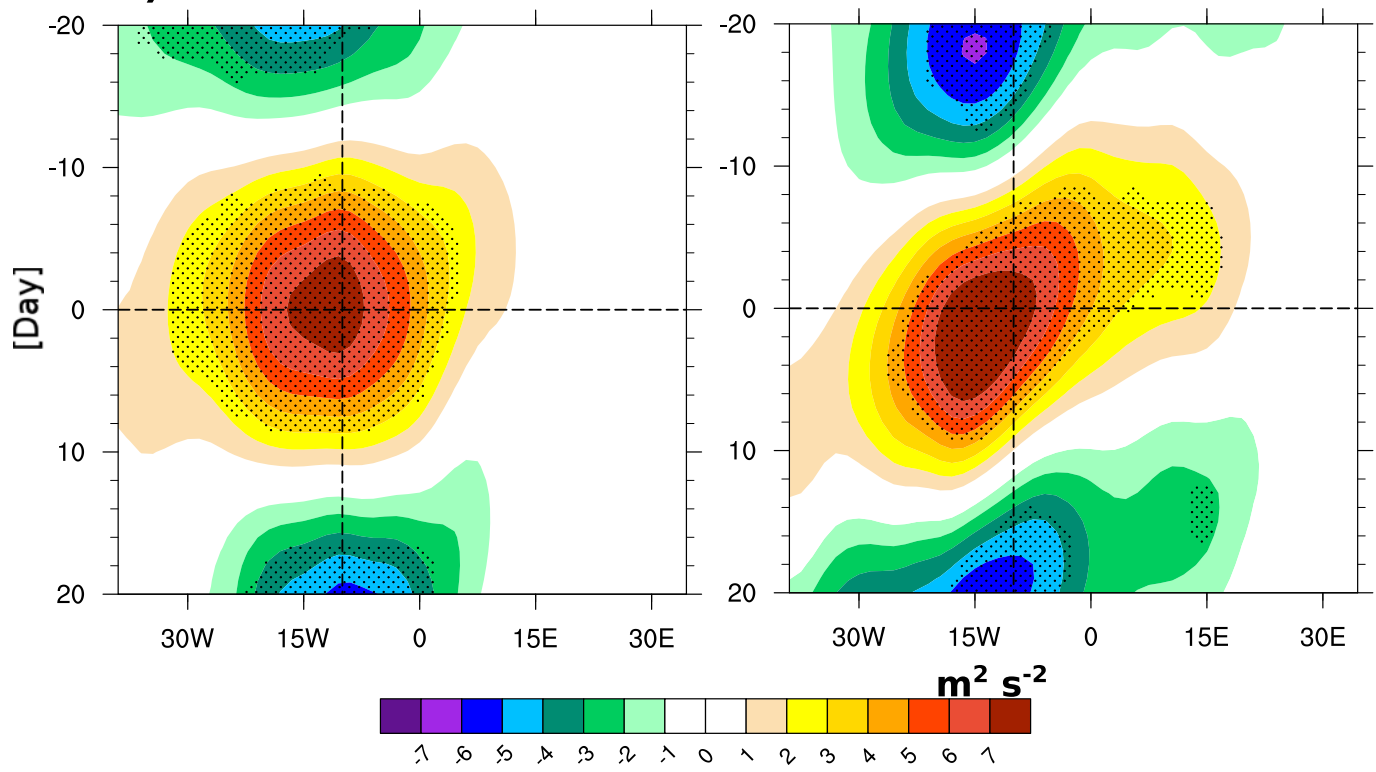

FIG. 11. Lead-lag composites for positive PKE events in June-September are averaged to create Hovmöller diagrams of 30-90-day 700-hPa PKE anomalies $\left(\mathrm{m}^{2} \mathrm{~s}^{-2}\right)$. MJO denial tests are averaged for different latitude bands: (a) $\mathrm{C} 1\left(10^{\circ}-20^{\circ} \mathrm{N}\right)$ and (b) S1 $\left(11^{\circ}-21^{\circ} \mathrm{N}\right)$. Stippling represents significance at the $95 \%$ confidence level.

oscillations than in $\mathrm{C} 1$, as is suggested by the interval between zero crossing times in Fig. 11. The period of intraseasonal oscillations in $\mathrm{C} 1$ is consistent with ERA-I (Fig. S4). These results suggest that the quasi-regular passage of dry, MJO-emitted Kelvin wave events along the equator is important for pacing intraseasonal variability in the WAM. Without the MJO influencing the time scale of events, the WAM region may prefer a faster internally generated intraseasonal oscillation, as demonstrated in these WRF simulations.

The extension of the AEJ (i.e., increase of easterly flow) into East Africa has been cited as important for the intraseasonal variability of AEWs (e.g., Leroux et al. 2010; Alaka and Maloney 2012) by increasing barotropic and baroclinic energy conversions through a sharpened meridional gradient of zonal wind and temperature (AM2014). An AEJ extension is clearly observed in all MJO simulations prior to the downstream PKE maximum (Fig. 12), which is also a robust East African feature in reanalysis data (AM2014). The similarity of the AEJ extension among the MJO simulations highlights that this is a common precursor to intraseasonal AEW activity, regardless of influence from the MJO. Zonal wind anomalies associated with this AEJ extension increase cyclonic vorticity in developing AEWs.

A stronger AEJ in East Africa is indicative of a larger reversal of the meridional potential vorticity gradient and increased barotropic-baroclinic energy conversions (e.g., Charney and Stern 1962). This strengthened meridional potential vorticity gradient reversal would aid in the growth of small, isolated convective events into more robust AEWs from combined barotropicbaroclinic instability. This implication for the energetics will be explored in the next section. In addition, the AEJ extension is in thermal wind balance with low-level 30-90-day temperature anomalies that may be related to fluctuations in the Saharan heat low (not shown). Previous studies have analyzed significant intraseasonal variability in the Saharan heat low (e.g., Lavaysse et al. 2009), which has been associated with a complex interaction with midlatitude flow (Chauvin et al. 2010; Roehrig et al. 2011). The impact of Saharan heat low fluctuations on intraseasonal AEW variability is a topic that will be investigated in future research.

\section{b. 30-90-day AEW energetics}

The intraseasonal variability of the PKE and PAPE budgets in WRF presented here is an extension of the analysis performed with ERA-I data in AM2014. We focus on the same four PKE creation terms introduced in section $3 \mathrm{~b}$. In the following analysis, three of the four modeled PKE creation terms $\left(B_{T}, B_{C}\right.$, and $\left.Q_{T}\right)$ exhibit qualitatively similar intraseasonal variability as in reanalysis data (see Fig. S5). Consistent with boreal summer mean results (see section 3b), simulated $\left\langle C_{\mathrm{pk}}\right\rangle_{30-90}$ is of the opposite sign to reanalysis fields due to the dominance of negative $\left\langle Q_{T}\right\rangle_{30-90}$ anomalies in the PAPE budget. 
a) $\mathrm{C1}$

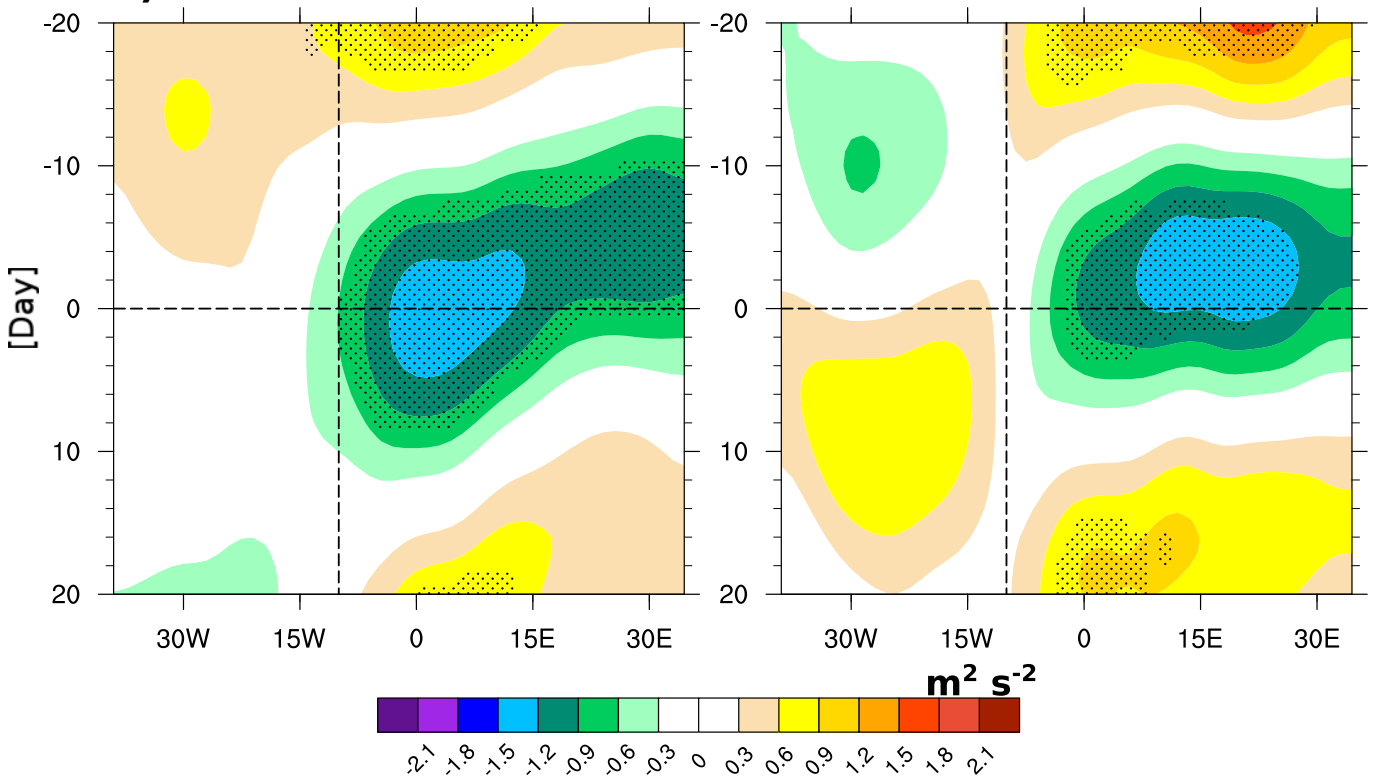

FIG. 12. As in Fig. 11, but for 30-90-day 650-hPa zonal wind anomalies $\left(\mathrm{m} \mathrm{s}^{-1}\right)$. MJO denial tests are plotted for different latitude bands: (a) $\mathrm{C} 1\left(12.5^{\circ}-17.5^{\circ} \mathrm{N}\right)$ and (b) $\mathrm{S} 1\left(15.5^{\circ}-20.5^{\circ} \mathrm{N}\right)$.

In the $\mathrm{C} 1$ simulation, $\left\langle B_{T}\right\rangle_{30-90}$ anomalies in East African lead those in West Africa by six days, although $\left\langle B_{T}\right\rangle_{30-90}$ anomalies do not clearly propagate westward through tropical North Africa. The separate $\left\langle B_{T}\right\rangle_{30-90}$ maxima in East and West Africa appear to be important for the initiation and maintenance of AEW activity on intraseasonal time scales, respectively (Fig. 13a). AM2014 also found that $\left\langle B_{T}\right\rangle_{30-90}$ anomalies were important for the maintenance of positive PKE events. East African $\left\langle B_{T}\right\rangle_{30-90}$ anomalies in $\mathrm{C} 1$ are directly related to an eastward extension and strengthening of the AEJ in this region (Fig. 12a). Earlier studies have noted this link between AEW initiation and an AEJ extension (e.g., Leroux and Hall 2009; Alaka and Maloney 2012; AM2014). The eastward extension of the AEJ sharpens the meridional momentum gradient to create $\langle\mathrm{PKE}\rangle_{30-90}$ through $\left\langle B_{T}\right\rangle_{30-90}$. East African $\left\langle B_{T}\right\rangle_{30-90}$ anomalies are an order of magnitude larger in $\mathrm{C} 1$ than in ERA-I, which highlights an increased role for $\left\langle B_{T}\right\rangle_{30-90}$ anomalies in the initiation of positive PKE events. In West Africa, $\left\langle B_{T}\right\rangle_{30-90}$ anomalies are $50 \%$ larger in $\mathrm{C} 1$ than in ERA-I during positive PKE events, which could be related to stronger meridional eddy momentum fluxes induced by stronger AEW circulations. Increased 700-hPa $\langle\mathrm{PKE}\rangle_{30-90}$ amplitudes in these simulations (Figs. 10 and 11) support this notion. The dominance of eddy momentum flux amplitude variations in fostering variability in $\left\langle B_{T}\right\rangle_{30-90}$ amplitudes in West Africa was noted in AM2014.
S1 produces significant $\left\langle B_{T}\right\rangle_{30-90}$ anomalies with amplitudes even larger than $\mathrm{C} 1$. Anomalies in East Africa precede those in West Africa by a few days. As in C1, East African $\left\langle B_{T}\right\rangle_{30-90}$ anomalies can be linked to an AEJ extension as shown in Fig. 12b. During positive PKE events, West African $\left\langle B_{T}\right\rangle_{30-90}$ anomalies in S1 (Fig. 14a) are 2 times larger than in C1 (Fig. 13a) and 3 times larger than in ERA-I (Fig. S5). The prominent $\left\langle B_{T}\right\rangle_{30-90}$ signal in these simulations reflects an important role for momentum gradients in the creation of West African PKE, irrespective of MJO forcing.

Previous studies have shown that baroclinic energy conversions are prominent for the initiation and maintenance of AEWs (e.g., Lau and Lau 1992; Hsieh and Cook 2007; AM2014). The initial driver of $\left\langle B_{C}\right\rangle_{30-90}$ anomalies is a meridional temperature gradient between the Sahara and equatorial Africa, which sharpens in East Africa prior to positive PKE events and is consistent with the jet extension shown in Fig. 12. Note that $\left\langle B_{C}\right\rangle_{30-90}$ in East Africa in C1 leads that in West Africa by about five days, consistent with the jet extension in that region that leads PKE events downstream. In C1, West African $\left\langle B_{C}\right\rangle_{30-90}$ anomalies are 2 times larger and are more collocated with $\left\langle B_{T}\right\rangle_{30-90}$ anomalies (Fig. 13c) than in ERA-I (Fig. S5). Since the relatively weak meridional temperature gradient in $\mathrm{C} 1$ (see Fig. 7c) would tend to reduce $\left\langle B_{C}\right\rangle_{30-90}$ anomalies across tropical North Africa compared to ERA-I, the increased magnitude of $\left\langle B_{C}\right\rangle_{30-90}$ anomalies relative to ERA-I is likely 

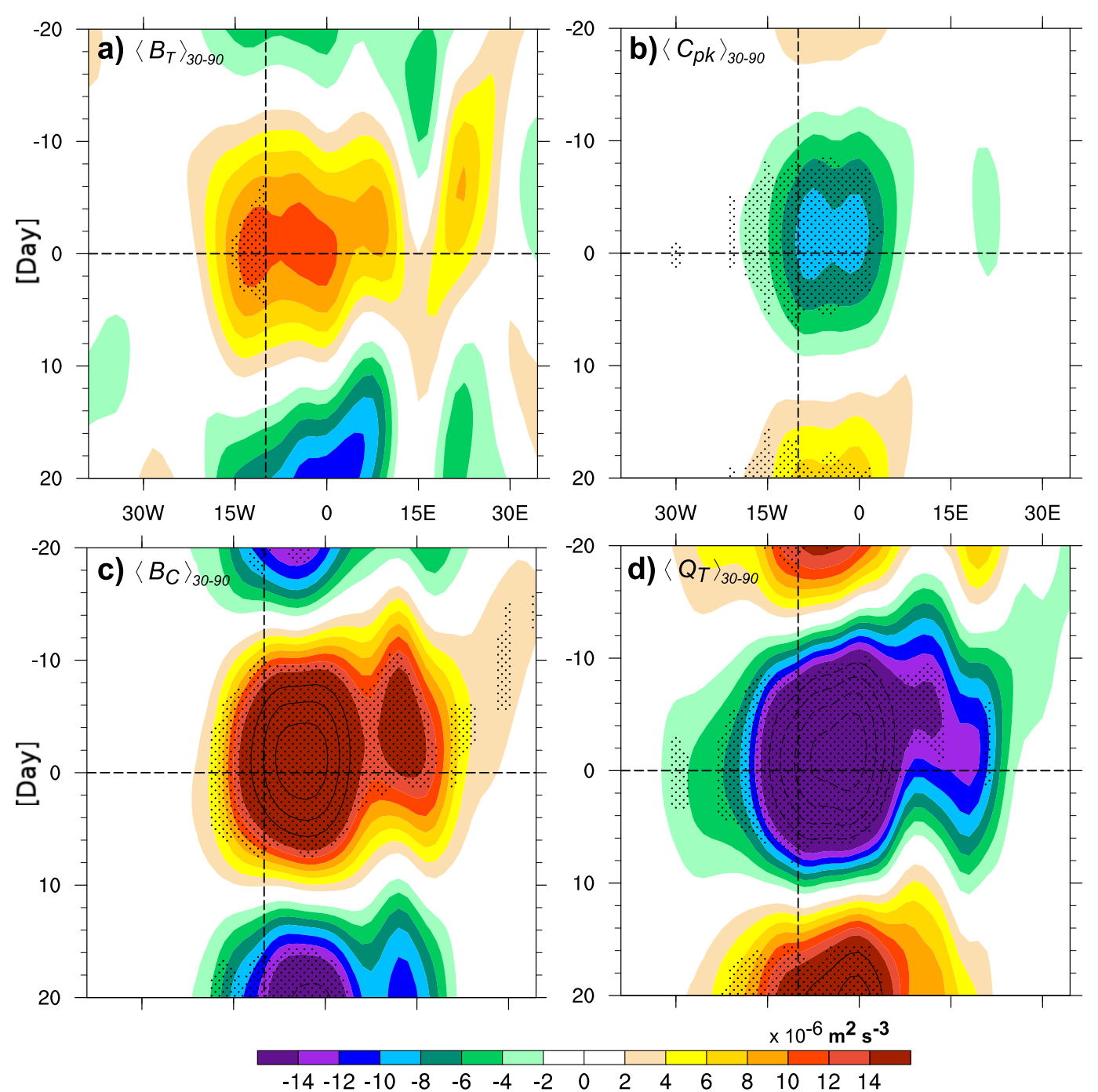

FIG. 13. As in Fig. 11, except for vertically averaged, 30-90-day PKE creation terms $\left(\mathrm{m}^{2} \mathrm{~s}^{-3}\right)$ from C1. Shown are (a) barotropic energy conversion, (b) baroclinic overturning, (c) baroclinic energy conversion, and (d) PAPE generation by diabatic heating. Lead/lag composites were averaged between $7.5^{\circ}$ and $12.5^{\circ} \mathrm{N}$ to create Hovmöller diagrams. Contours represent levels outside of the shading interval.

associated with the stronger AEW circulations (Figs. 5a,b) that flux more heat across the background meridional temperature gradient.

As in $\mathrm{C} 1,\left\langle B_{C}\right\rangle_{30-90}$ anomalies in S1 are initially generated in East Africa associated with the extended jet, and then propagate downstream into West Africa (Fig. 14c). Prior to positive PKE events, $\left\langle B_{C}\right\rangle_{30-90}$ anomalies propagate faster into West Africa in S1 $\left(\sim 7 \mathrm{~m} \mathrm{~s}^{-1}\right)$ than in $\mathrm{C} 1\left(\sim 3.5 \mathrm{~m} \mathrm{~s}^{-1}\right)$. The importance of $\left\langle B_{C}\right\rangle_{30-90}$ in East Africa to the initiation of PKE events, specifically through meridional eddy heat fluxes, is a robust result in these simulations that is consistent with AM2014. This precursor signal in East Africa is present whether or not MJO forcing occurs at the boundaries.
The shorter time scale of the variability in S1 versus $\mathrm{C} 1$ can also be discerned in the evolution of energy budget terms, such as $\left\langle B_{C}\right\rangle_{30-90}$ and $\left\langle B_{T}\right\rangle_{30-90}$, when comparing Figs. 12 and 13 , suggesting that the MJO might play some role in pacing the timing and influencing the time scale of intraseasonal events in West Africa.

Part of the motivation to examine modeled 30-90-day AEW energetics is to test the robustness of PAPE generation caused by diabatic heating anomalies $\left(\left\langle Q_{T}\right\rangle\right)$ that we derived in ERA-I (AM2014). Previous studies argued that diabatic heating in East Africa is vital for the initiation of AEWs (Thorncroft et al. 2008; Alaka and Maloney 2012; Berry and Thorncroft 2012). AM2014 suggested that a poor representation of diabatic heating 

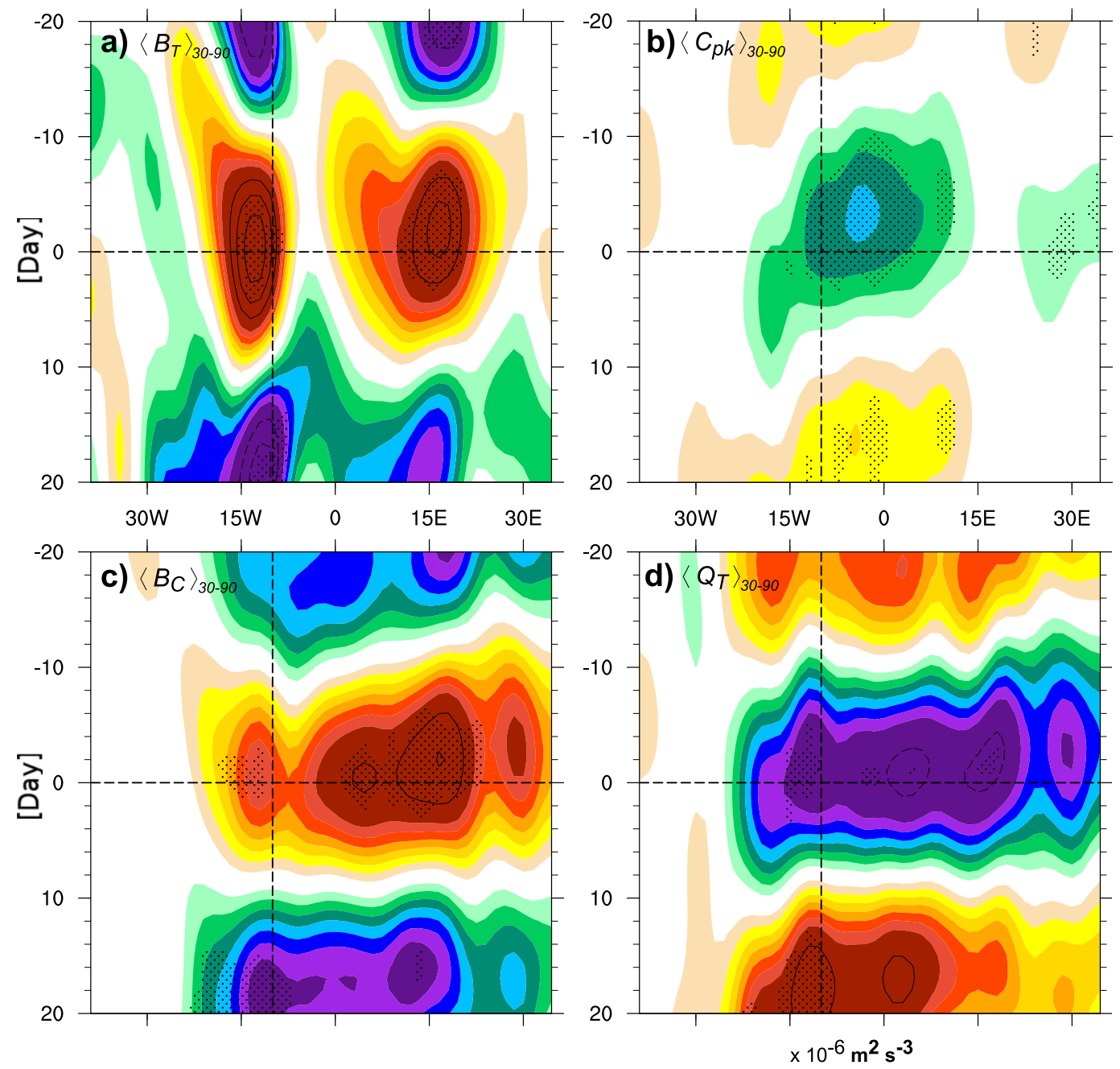

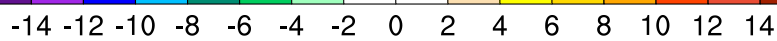

FIG. 14. As in Fig. 13, but for S1.

(and related processes) in the ERA-I dataset limited the role of this term in East Africa in initiating periods of strong MJO-induced AEW activity. However, the WRF simulations here do not support a role for diabatic heating in the initiation of positive PKE events in East Africa (Figs. 13d and 14d). The dominant role of $\left\langle Q_{T}\right\rangle_{30-90}$ anomalies in these simulations is to act as a negative feedback to AEW growth across tropical North Africa, which reduces the PAPE available for PKE creation (Figs. 13 and 14), consistent with that in ERA-I (Fig. S5). In both the $\mathrm{C} 1$ and $\mathrm{S} 1$ simulations, $\left\langle Q_{T}\right\rangle_{30-90}$ anomalies preceding PKE events are negative in East Africa, and then these negative anomalies propagate westward and are strongly collocated with $\left\langle B_{C}\right\rangle_{30-90}$ anomalies, generally consistent with ERA-I results. Hence, the WRF simulations here support the contention from ERA-I that diabatic heating in East Africa is not an important trigger for downstream intraseasonal PKE events in West Africa.

Given the cancellation of $\left\langle B_{C}\right\rangle_{30-90}$ and $\left\langle Q_{T}\right\rangle_{30-90}$ anomalies in the simulations, $\left\langle C_{\mathrm{pk}}\right\rangle_{30-90}$ anomalies are weakly negative. In ERA-I, $\left\langle B_{C}\right\rangle_{30-90}$ anomalies are positive as AEWs grow on the strong meridional temperature gradient between the Sahara and the Gulf of Guinea, while $\left\langle Q_{T}\right\rangle_{30-90}$ anomalies represent a negative feedback to AEW circulations (see AM2014). Although simulated $\left\langle B_{C}\right\rangle_{30-90}$ and $\left\langle Q_{T}\right\rangle_{30-90}$ individually maintain the same sign as in AM2014, their relative magnitudes are reversed, with negative $\left\langle Q_{T}\right\rangle_{30-90}$ anomalies of larger magnitude than $\left\langle B_{C}\right\rangle_{30-90}$ anomalies, causing a net destruction of PKE by $\left\langle C_{\mathrm{pk}}\right\rangle_{30-90}$ anomalies (Figs. 13b and 14b). 


\section{Conclusions and discussion}

Given the societal impacts of AEWs in the droughtvulnerable Sahel region, efforts have been undertaken to increase the predictability of these synoptic-scale eddies by better understanding how they are modulated by dominant large-scale phenomena, such as the MJO. Although regional climate models have been utilized to successfully simulate the WAM region, including the AEJ and AEWs, only a few studies have employed models to investigate intraseasonal variability of the WAM (Gallée et al. 2004; Taylor 2008; Flaounas et al. 2011). This work used WRF to understand the processes that control the intraseasonal variability of the WAM, including AEW activity.

The primary goal of this study was to assess the role of external forcing on intraseasonal variability in the WAM through a data denial technique. In two sensitivity tests, 30-90-day variability was completely removed (S1) and partially (i.e., only eastward-propagating signals) removed (S2) from the WRF boundary conditions to investigate the importance of external forcing (e.g., MJO) on WAM variability. These experiments were compared with a control simulation (C1), in which no filtering was performed. Overall, $\mathrm{C} 1$ provided confidence that WRF can reproduce primary features (i.e., AEWs, AEJ, precipitation) of the WAM, even in a decade-long simulation.

Our main conclusions from the MJO denial tests are highlighted here:

- Intraseasonal variability in the WAM is dominated by internal variability in WRF. In the absence of 30-90-day variability in the boundary conditions, the S1 and S2 simulations exhibit AEW activity that resembles results from $\mathrm{C} 1$ and reanalysis products.

- The MJO (in particular, eastward-propagating variability such as Kelvin waves forced by the MJO) appears to be important for setting the time scale of intraseasonal variability in West Africa. In the absence of MJO forcing, the time scale of intraseasonal oscillations appears to decrease. The eastwardpropagating variability in the MJO band that enters the WAM domain from the west may act like a pacemaker for this region.

- Westward-propagating 30-90-day disturbances (e.g., equatorial Rossby waves) have little role in the amplitude and evolution of intraseasonal PKE events in the model. This is reflected by the strong similarity of the $\mathrm{S} 1$ and $\mathrm{S} 2$ simulations.

- An extension of the AEJ prior to positive PKE events is a robust feature in reanalyses and model output. The AEJ extension, which was also noted in
ERA-I (Alaka and Maloney 2012), appears to be produced through internal dynamics of the WAM system in isolation from intraseasonal forcing at the boundaries. The AEJ extension is associated with a sharpened surface temperature gradient, which indicates stronger barotropic-baroclinic instability, and a potential connection to the Saharan heat low.

- Both barotropic and baroclinic energy conversions are important for the initiation and maintenance of positive PKE events in all WAM simulations, regardless of intraseasonal forcing at the boundaries. The large amplitudes of modeled $\left\langle B_{C}\right\rangle_{30-90}$ and $\left\langle B_{T}\right\rangle_{30-90}$ relative to ERA-I reflect stronger AEW circulations and stronger eddy fluxes.

- For all simulations, $\left\langle Q_{T}\right\rangle_{30-90}$ is responsible for PAPE destruction and consequently PKE destruction $\left(\left\langle C_{\mathrm{pk}}\right\rangle_{30-90}<0\right)$ in East Africa prior to positive PKE events, which calls into question the vitality of diabatic heating in this region for initiating intraseasonal PKE events. This result is generally consistent with ERA-I results (AM2014). However, destruction of PAPE by $\left\langle Q_{T}\right\rangle_{30-90}$ is actually of slightly larger magnitude than generation by $\left\langle B_{C}\right\rangle_{30-90}$, a somewhat surprising result that is the opposite of that seen in ERA-I. The sensitivity of $\left\langle Q_{T}\right\rangle_{30-90}$ to cumulus parameterization and related temperature errors will be a topic of future research.

These results are not dependent upon the use of a local, area-averaged 700-hPa PKE index. Results were robust when a multivariate MJO index (Wheeler and Hendon 2004) was used to assess 30-90-day variability in $\mathrm{C} 1$ (not shown). MJO phase composites produced from $\mathrm{C} 1$ were generally similar to those produced from ERA-I (Alaka and Maloney 2012), providing confidence that modeled 30-90-day WAM variability was consistent with observations.

In the interpretation of the aforementioned conclusions, it is important to remember that WRF is just one tool that may be utilized to study intraseasonal variability of the WAM. In results presented here, WRF and other products (i.e., ERA-I, TRMM) exhibit some noticeable discrepancies in the WAM region (see Figs. 3-5). In fact, biases in $\mathrm{C} 1$ compared with ERA-I/TRMM were larger than differences between $\mathrm{C} 1$ and sensitivity tests. For example, modeled precipitation was at least double that from TRMM over land, including excessive rainfall in East Africa. WRF consistently produced a precipitation maximum $>20 \mathrm{~mm} \mathrm{day}^{-1}$ near the Ethiopian highlands. In addition, the AEJ core was shifted poleward by $5^{\circ}$, was weaker, and was less defined in WRF. While lower-tropospheric westerlies also shifted north in WRF, this monsoon flow was stronger in $\mathrm{C} 1$ than in 
ERA-I. PKE amplitude and structure were also quite different in WRF, although the structure of modeled AEWs was consistent with ERA-I (see Fig. 6). Consequently, differences between $\mathrm{C} 1$ and $\mathrm{S} 1$ may not be systematic and may instead reflect the failure of WRF to reproduce basic elements of the WAM. However, the large sample size (10 seasons) of the model output provides confidence in the differences between $\mathrm{C} 1$ and $\mathrm{S} 1$, even though they are smaller than model biases.

Despite these biases, a lack of ground-based observations in the WAM region suggests that TRMM and ERA-I are not perfect baselines. For example, satellite-based precipitation retrievals over Africa are questionable given complex land emissivity and the lack of a coherent rain gauge network for reference. Roca et al. (2010) found that TRMM datasets tended to overestimate extreme rainfall in the WAM. In addition, the mean state of ERA-I in the WAM region may be biased by nearby data-rich regions (e.g., Europe). Overall, these results highlight the need for more research into the nature of intraseasonal variability in the WAM system, with a focus on how internal intraseasonal variability is governed.

Acknowledgments. This work was supported by the Climate and Large-Scale Dynamics Program of the National Science Foundation under Grant AGS1347738. ERA-I data were provided courtesy of Meteorological Archival and Retrieval System (MARS) at ECMWF. TRMM 3B42 data were provided courtesy of NASA. The authors thank Walter Hannah, Adam Rydbeck, and Brandon Wolding, whose insights were invaluable throughout the study. The authors would also like to thank three anonymous reviewers, whose helpful comments helped strengthen this manuscript.

\section{REFERENCES}

Abiodun, B. J., J. S. Pal, E. A. Afiesimama, W. J. Gutowski, and A. Adedoyin, 2008: Simulation of West African monsoon using RegCM3. Part II: Impacts of deforestation and desertification. Theor. Appl. Climatol., 93, 245-261, doi:10.1007/ s00704-007-0333-1.

Afiesimama, E. A., J. S. Pal, B. J. Abiodun, W. J. Gutowski, and A. Adedoyin, 2006: Simulation of West African monsoon using the RegCM3. Part I: Model validation and interannual variability. Theor. Appl. Climatol., 86, 23-37, doi:10.1007/ s00704-005-0202-8.

Alaka, G. J., 2014: African easterly wave energetics on intraseasonal timescales. Ph.D. thesis, Department of Atmospheric Science, Colorado State University, $214 \mathrm{pp}$.

_ , and E. D. Maloney, 2012: The influence of the MJO on upstream precursors to African easterly waves. J. Climate, 25, 3219-3236, doi:10.1175/JCLI-D-11-00232.1.

- and - 2014: The intraseasonal variability of African easterly wave energetics. J. Climate, 27, 6559-6580, doi:10.1175/ JCLI-D-14-00146.1.
Ali, A., A. Amani, A. Diedhiou, and T. Lebel, 2005: Rainfall estimation in the Sahel. Part II: Evaluation of rain gauge networks in the CILSS countries and objective intercomparison of rainfall products. J. Appl. Meteor., 44, 1707-1722, doi:10.1175/ JAM2305.1.

Berry, G. J., and C. D. Thorncroft, 2012: African easterly wave dynamics in a mesoscale numerical model: The upscale role of convection. J. Atmos. Sci., 69, 1267-1283, doi:10.1175/ JAS-D-11-099.1.

Carlson, T. N., 1969: Synoptic histories of three African disturbances that developed into Atlantic hurricanes. Mon. Wea. Rev., 97, 256-276, doi:10.1175/1520-0493(1969)097<0256: SHOTAD $>2.3$.CO;2.

Charney, J. G., and M. E. Stern, 1962: On the stability of internal baroclinic jets in a rotating atmosphere. J. Atmos. Sci., 19, 159172, doi:10.1175/1520-0469(1962)019<0159:OTSOIB > 2.0.CO;2.

Chauvin, F., R. Roehrig, and J.-P. Lafore, 2010: Intraseasonal variability of the Saharan heat low and its link with midlatitudes. J. Climate, 23, 2544-2561, doi:10.1175/2010JCLI3093.1.

Chou, M.-D., and M. J. Suarez, 1999: A solar radiation parameterization for atmospheric studies. NASA Tech. Rep. Series on Global Modeling and Data Assimilation, NASA/TM-1999104606, Vol. 15, 40 pp.

Cook, K. H., and E. K. Vizy, 2013: Projected changes in East African rainy seasons. J. Climate, 26, 5931-5948, doi:10.1175/ JCLI-D-12-00455.1.

Crétat, J., E. K. Vizy, and K. H. Cook, 2015: The relationship between African easterly waves and daily rainfall over West Africa: Observations and regional climate simulations. Climate Dyn., 44, 385-404, doi:10.1007/s00382-014-2120-x.

Dee, D. P., and Coauthors, 2011: The ERA-Interim reanalysis: Configuration and performance of the data assimilation system. Quart. J. Roy. Meteor. Soc., 137, 553-597, doi:10.1002/qj.828.

Diedhiou, A., S. Janicot, A. Viltard, and P. de Félice, 2002: Energetics of easterly wave disturbances over West Africa and the tropical Atlantic: A climatology from the 1979-95 NCEP/ NCAR reanalyses. Climate Dyn., 18, 487-500, doi:10.1007/ s00382-001-0195-7.

Druyan, L. M., and Coauthors, 2010: The WAMME regional model intercomparison study. Climate Dyn., 35, 175-192, doi:10.1007/s00382-009-0676-7.

Ek, M. B., K. E. Mitchell, Y. Lin, E. Rogers, P. Grunmann, V. Koren, G. Gayno, and J. D. Tarpley, 2003: Implementation of Noah land surface model advances in the National Centers for Environmental Prediction operational mesoscale Eta model. J. Geophys. Res., 108, 8851, doi:10.1029/2002JD003296.

Fisher, R. A., 1915: Frequency distribution of the values of the correlation coefficient in samples from an indefinitely large population. Biometrika, 10, 507-521.

, 1921: On the "probable error" of a coefficient of correlation deduced from a small sample. Metron, 1, 3-32.

Flaounas, E., S. Bastin, and S. Janicot, 2011: Regional climate modelling of the 2006 West African monsoon: Sensitivity to convection and planetary boundary layer parameterisation using WRF. Climate Dyn., 36, 1083-1105, doi:10.1007/ s00382-010-0785-3.

Gaetani, M., B. Fontaine, P. Roucou, and M. Baldi, 2010: Influence of the Mediterranean Sea on the West African monsoon: Intraseasonal variability in numerical simulations. J. Geophys. Res., 115, D24115, doi:10.1029/2010JD014436.

Gallée, H., and Coauthors, 2004: A high-resolution simulation of a West African rainy season using a regional climate model. J. Geophys. Res., 109, D05108, doi:10.1029/2003JD004020. 
Gill, A. E., 1980: Some simple solutions for heat-induced tropical circulation. Quart J. Roy. Meteor. Soc., 106, 447-462, doi:10.1002/qj.49710644905.

Gilman, D. L., F. J. Fuglister, and J. M. Mitchell, 1963: On the power spectrum of "red noise." J. Atmos. Sci., 20, 182-184, doi:10.1175/1520-0469(1963)020<0182:OTPSON>2.0.CO;2.

Goldenberg, S. B., and L. J. Shapiro, 1996: Physical mechanisms for the association of El Niño and West African rainfall with Atlantic major hurricane activity. J. Climate, 9, 1169-1187, doi:10.1175/1520-0442(1996)009<1169:PMFTAO>2.0.CO;2.

Grell, G. A., and D. Devenyi, 2002: A generalized approach to parameterizing convection combining ensemble and data assimilation techniques. Geophys. Res. Lett., 29, 1963, doi:10.1029/2002GL015311.

— J. Dudhia, and D. Stauffer, 1994: A description of the fifth generation Penn State/NCAR mesoscale model (MM5). NCAR Tech. Note NCAR/TN-398-STR, 117 pp.

Hall, N. M. J., G. N. Kiladis, and C. D. Thorncroft, 2006: Threedimensional structure and dynamics of African easterly waves. Part II: Dynamical modes. J. Atmos. Sci., 63, 2231-2245, doi:10.1175/JAS3742.1.

Heckley, W. A., and A. E. Gill, 1984: Some simple analytical solutions to the problem of forced equatorial long waves. Quart. J. Roy. Meteor. Soc., 110, 203-217, doi:10.1002/qj.49711046314.

Hong, S.-Y., and J.-O. J. Lim, 2006: The WRF single-moment 6-class microphysics scheme (WSM6). J. Korean Meteor. Soc., 42, 129-151.

Hsieh, J.-S., and K. H. Cook, 2005: Generation of African easterly wave disturbances: Relationship to the African easterly jet. Mon. Wea. Rev., 133, 1311-1327, doi:10.1175/MWR2916.1.

_, and _ 2007: A study of the energetics of African easterly waves using a regional climate model. J. Atmos. Sci., 64, 421440, doi:10.1175/JAS3851.1.

, and - 2008: On the instability of the African easterly jet and the generation of African waves: Reversals of the potential vorticity gradient. J. Atmos. Sci., 65, 2130-2151, doi:10.1175/2007JAS2552.1.

Janicot, S., F. Mounier, N. M. J. Hall, S. Leroux, B. Sultan, and G. N. Kiladis, 2009: Dynamics of the West African monsoon. Part IV: Analysis of 25-90-day variability of convection and the role of the Indian monsoon. J. Climate, 22, 1541-1565, doi:10.1175/2008JCLI2314.1.

— African monsoon. Atmos. Sci. Lett., 12, 58-66, doi:10.1002/ asl.280.

Janjic, Z. I., 1994: The step-mountain eta coordinate model: Further developments of the convection, viscous sublayer, and turbulence closure schemes. Mon. Wea. Rev., 122, 927-945, doi:10.1175/1520-0493(1994)122<0927:TSMECM>2.0.CO;2.

Kiladis, G. N., C. D. Thorncroft, and N. M. J. Hall, 2006: Threedimensional structure and dynamics of African easterly waves. Part I: Observations. J. Atmos. Sci., 63, 2212-2230, doi:10.1175/JAS3741.1.

Kummerow, C., W. Barnes, T. Kozu, J. Shiue, and J. Simpson, 1998: The Tropical Rainfall Measuring Mission (TRMM) sensor package. J. Atmos. Oceanic Technol., 15, 809-817, doi:10.1175/ 1520-0426(1998)015<0809:TTRMMT>2.0.CO;2.

Lafore, J.-P., C. Flamant, V. Giraud, F. Guichard, P. Knippertz, J.-F. Mahfouf, P. Mascart, and E. R. Williams, 2010: Introduction to the AMMA special issue on 'Advances in understanding atmospheric processes over West Africa through the AMMA field campaign.' Quart. J. Roy. Meteor. Soc., 136 (Suppl. 1), 2-7, doi:10.1002/qj.583.
Landsea, C. W., G. D. Bell, W. M. Gray, and S. B. Goldenberg, 1998: The extremely active 1995 Atlantic hurricane season: Environmental conditions and verification of seasonal forecasts. Mon. Wea. Rev., 126, 1174-1193, doi:10.1175/ 1520-0493(1998)126<1174:TEAAHS > 2.0.CO;2.

Lau, K.-H., and N.-C. Lau, 1992: The energetics and propagation dynamics of tropical summertime synoptic-scale disturbances. Mon. Wea. Rev., 120, 2523-2539, doi:10.1175/ 1520-0493(1992)120<2523:TEAPDO > 2.0.CO;2.

Lavaysse, C., C. Flamant, S. Janicot, D. J. Parker, J.-P. Lafore, B. Sultan, and J. Pelon, 2009: Seasonal evolution of the West African heat low: A climatological perspective. Climate Dyn., 33, 313-330, doi:10.1007/s00382-009-0553-4.

Lavender, S. L., and A. J. Matthews, 2009: Response of the West African monsoon to the Madden-Julian oscillation. J. Climate, 22, 4097-4116, doi:10.1175/2009JCLI2773.1.

— C. M. Taylor, and A. J. Matthews, 2010: Coupled landatmosphere intraseasonal variability of the West African monsoon in a GCM. J. Climate, 23, 5557-5571, doi:10.1175/ 2010JCLI3419.1.

Leroux, S., and N. M. J. Hall, 2009: On the relationship between African easterly waves and the African easterly jet. J. Atmos. Sci., 66, 2303-2316, doi:10.1175/2009JAS2988.1.

- — , and G. N. Kiladis, 2010: A climatological study of transient-mean-flow interactions over West Africa. Quart J. Roy. Meteor. Soc., 136, 397-410, doi:10.1002/qj.474.

Madden, R. A., and P. R. Julian, 1971: Detection of a 40-50 day oscillation in the zonal wind in the tropical Pacific. J. Atmos. Sci., 28, 702-708, doi:10.1175/1520-0469(1971)028<0702: DOADOI $>2.0 . \mathrm{CO} ; 2$.

Maloney, E. D., and J. Shaman, 2008: Intraseasonal variability of the West African monsoon and Atlantic ITCZ. J. Climate, 21, 2898-2918, doi:10.1175/2007JCLI1999.1.

Matthews, A. J., 2004: Intraseasonal variability over tropical Africa during northern summer. J. Climate, 17, 2427-2440, doi:10.1175/1520-0442(2004)017<2427:IVOTAD>2.0.CO;2.

Mekonnen, A., C. D. Thorncroft, and A. R. Aiyyer, 2006: Analysis of convection and its association with African easterly waves. J. Climate, 19, 5405-5421, doi:10.1175/JCLI3920.1.

Monin, A. S., and A. M. Obukhov, 1954: Basic laws of turbulent mixing in the surface layer of the atmosphere. Contrib. Geophys. Inst. Acad. Sci. USSR, 151, 163-187.

Mounier, F., S. Janicot, and G. N. Kiladis, 2008: The West African monsoon dynamics. Part III: The quasi-biweekly zonal dipole. J. Climate, 21, 1911-1928, doi:10.1175/2007JCLI1706.1.

Nicholson, S. E., 2013: The West African Sahel: A review of recent studies on the rainfall regime and its interannual variability. ISRN Meteor., 2013, 453521, doi:10.1155/2013/453521.

Nikulin, G., and Coauthors, 2012: Precipitation climatology in an ensemble of CORDEX-Africa regional climate simulations. J. Climate, 25, 6057-6078, doi:10.1175/JCLI-D-11-00375.1

Noble, E., L. M. Druyan, and M. Fulakeza, 2014: The sensitivity of WRF daily summertime simulations over West Africa to alternative parameterizations. Part I: African wave circulation. Mon. Wea. Rev., 142, 1588-1608, doi:10.1175/MWR-D-13-00194.1.

Norquist, D. C., E. E. Recker, and R. J. Reed, 1977: The energetics of African wave disturbances as observed during phase III of GATE. Mon. Wea. Rev., 105, 334-342, doi:10.1175/ 1520-0493(1977)105<0334:TEOAWD>2.0.CO;2.

Paeth, H., K. Born, R. Podzun, and D. Jacob, 2005: Regional dynamical downscaling over West Africa: Model evaluation and comparison of wet and dry years. Meteor. Z., 14, 349-367, doi:10.1127/0941-2948/2005/0038. 
Pohl, B., and H. Douville, 2011: Diagnosing GCM errors over West Africa using relaxation experiments. Part II: Intraseasonal variability and African easterly waves. Climate Dyn., 37, 13131334, doi:10.1007/s00382-011-1106-1.

Roca, R., P. Chambon, I. Jobard, P. E. Kirstetter, M. Gosset, and J. C. Bergès, 2010: Comparing satellite and surface rainfall products over West Africa at meteorologically relevant scales during the AMMA campaign using error estimates. J. Appl. Meteor. Climatol., 49, 715-731, doi:10.1175/2009JAMC2318.1.

Roehrig, R., F. Chauvin, and J. P. Lafore, 2011: 10-25-day intraseasonal variability of convection over the Sahel: A role of the Saharan heat low and midlatitudes. J. Climate, 24, 5863-5878, doi:10.1175/2011JCLI3960.1.

, D. Bouniol, F. Guichard, F. Hourdin, and J. L. Redelsperger, 2013: The present and future of the West African monsoon: A process-oriented assessment of CMIP5 simulations along the AMMA transect. J. Climate, 26, 6471-6505, doi:10.1175/ JCLI-D-12-00505.1.

Ross, R. S., T. N. Krishnamurti, and S. Pattnaik, 2012: Interactions of diabatic heating in convective superbursts with energy conversion processes in the genesis of Cape Verde hurricanes from African easterly waves. Mon. Wea. Rev., 140, 748-773, doi:10.1175/2011MWR3621.1.

Rydbeck, A. V., and E. D. Maloney, 2014: Energetics of east Pacific easterly waves during intraseasonal events. J. Climate, 27, 7603-7621, doi:10.1175/JCLI-D-14-00211.1.

_, _ - S.-P. Xie, J. Hafner, and J. Shaman, 2013: Remote forcing versus local feedback of east Pacific intraseasonal variability during boreal summer. J. Climate, 26, 3575-3596, doi:10.1175/JCLI-D-12-00499.1.

Skamarock, W. C., and J. B. Klemp, 2008: A time-split nonhydrostatic atmospheric model for weather research and forecasting applications. J. Comput. Phys., 227, 3465-3485, doi:10.1016/j.jcp.2007.01.037.

Smirnova, T. G., J. M. Brown, S. G. Benjamin, and D. Kim, 2000: Parameterization of cold-season processes in the MAPS landsurface scheme. J. Geophys. Res., 105, 4077-4086, doi:10.1029/ 1999JD901047.

Sobel, A., and E. Maloney, 2012: An idealized semi-empirical framework for modeling the Madden-Julian oscillation. J. Atmos. Sci., 69, 1691-1705, doi:10.1175/JAS-D-11-0118.1.

Sylla, M. B., E. Coppola, L. Mariotti, F. Giorgi, P. M. Ruti, A. Dell'Aquila, and X. Bi, 2010: Multiyear simulation of the African climate using a regional climate model (RegCM3) with the high resolution ERA-Interim reanalysis. Climate Dyn., 35, 231-247, doi:10.1007/s00382-009-0613-9.

_- I. Diallo, and J. S. Pal, 2013: West African monsoon in stateof-the-science regional climate models. Climate VariabilityRegional and Thematic Patterns, A. Tarhule, Ed., InTech, 3-36, doi:10.5772/55140.

Taylor, C. M., 2008: Intraseasonal land-atmosphere coupling in the West African monsoon. J. Climate, 21, 6636-6648, doi:10.1175/ 2008JCLI2475.1.
Thompson, G., P. R. Field, R. M. Rasmussen, and W. D. Hall, 2008: Explicit forecasts of winter precipitation using an improved bulk microphysics scheme. Part II: Implementation of a new snow parameterization. Mon. Wea. Rev., 136, 5095-5115, doi:10.1175/2008MWR2387.1.

Thorncroft, C. D., and K. Hodges, 2001: African easterly wave variability and its relationship to Atlantic tropical cyclone activity. J. Climate, 14, 1166-1179, doi:10.1175/1520-0442(2001)014<1166: AEWVAI $>2.0 . \mathrm{CO} ; 2$

—, N. M. J. Hall, and G. N. Kiladis, 2008: Three-dimensional structure and dynamics of African easterly waves. Part III: Genesis. J. Atmos. Sci., 65, 3596-3607, doi:10.1175/ 2008JAS2575.1.

Tian, Y., C. D. Peters-Lidard, B. J. Choudhury, and M. Garcia, 2007: Multitemporal analysis of TRMM-based satellite precipitation products for land data assimilation applications. J. Hydrometeor., 8, 1165-1183, doi:10.1175/2007JHM859.1.

Torn, R. D., 2010: Ensemble-based sensitivity analysis applied to African easterly waves. Wea. Forecasting, 25, 61-78, doi:10.1175/2009WAF2222255.1.

Ventrice, M. J., and C. D. Thorncroft, 2013: The role of convectively coupled atmospheric Kelvin waves on African easterly wave activity. Mon. Wea. Rev., 141, 1910-1924, doi:10.1175/MWR-D-12-00147.1.

- — , and P. E. Roundy, 2011: The Madden-Julian oscillation's influence on African easterly waves and downstream tropical cyclogenesis. Mon. Wea. Rev., 139, 2704-2722, doi:10.1175/MWR-D-10-05028.1.

Vizy, E. K., and K. H. Cook, 2002: Development and application of a mesoscale climate model for the tropics: Influence of sea surface temperature anomalies on the West African monsoon. J. Geophys. Res., 107, 4023, doi:10.1029/ 2001JD000686.

Wheeler, M. C., and G. N. Kiladis, 1999: Convectively coupled equatorial waves: Analysis of clouds and temperature in the wavenumber-frequency domain. J. Atmos. Sci., 56, 374-399, doi:10.1175/1520-0469(1999)056<0374: $\mathrm{CCEWAO}>2.0 . \mathrm{CO} ; 2$

_ , and H. H. Hendon, 2004: An all-season real-time multivariate MJO index: Development of an index for monitoring and prediction. Mon. Wea. Rev., 132, 1917-1932, doi:10.1175/ 1520-0493(2004)132<1917:AARMMI>2.0.CO;2.

Wolters, D., C. C. van Heerwaarden, J. Vilà-Guerau de Arellano, B. Cappelaere, and D. Ramier, 2010: Effects of soil moisture gradients on the path and the intensity of a West African squall line. Quart. J. Roy. Meteor. Soc., 136, 2162-2175, doi:10.1002/qj.712.

Wu, M.-L. C., O. Reale, and S. D. Schubert, 2013: A characterization of African easterly waves on 2.5-6-day and 6-9-day time scales. J. Climate, 26, 6750-6774, doi:10.1175/ JCLI-D-12-00336.1.

Zhang, C., 2005: Madden-Julian oscillation. Rev. Geophys., 43, RG2003, doi:10.1029/2004RG000158. 